\title{
Intercomparison of aerosol extinction profiles retrieved from MAX-DOAS measurements
}

\author{
U. Frieß ${ }^{1}$, H. Klein Baltink ${ }^{2}$, S. Beirle ${ }^{3}$, K. Clémer ${ }^{4, a}$, F. Hendrick ${ }^{4}$, B. Henzing ${ }^{5}$, H. Irie $^{6}$, G. de Leeuw ${ }^{5,7,8}$, A. Li ${ }^{9}$, M.

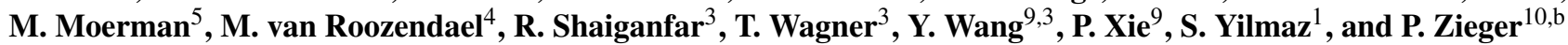 \\ ${ }^{1}$ Institute of Environmental Physics, University of Heidelberg, Heidelberg, Germany \\ ${ }^{2}$ Royal Netherlands Meteorological Institute (KNMI), De Bilt, the Netherlands \\ ${ }^{3}$ Max Planck Institute for Chemistry, Mainz, Germany \\ ${ }^{4}$ BIRA-IASB, Brussels, Belgium \\ ${ }^{5}$ Netherlands Organization for Applied Scientific Research (TNO), Utrecht, the Netherlands \\ ${ }^{6}$ Center for Environmental Remote Sensing, Chiba University, Chiba, Japan \\ ${ }^{7}$ Finnish Meteorological Institute (FMI), Helsinki, Finland \\ ${ }^{8}$ Department of Physics, University of Helsinki, Helsinki, Finland \\ ${ }^{9}$ Anhui Institute of Optics and Fine Mechanics, Chinese Academy of Sciences, Hefei, China \\ ${ }^{10}$ Laboratory of Atmospheric Chemistry, Paul Scherrer Institute, Villigen, Switzerland \\ ${ }^{a}$ now at: Institute of Astronomy, Leuven University, Leuven, Belgium \\ ${ }^{b}$ now at: Department of Environmental Science and Analytical Chemistry, Stockholm University, Stockholm, Sweden
}

Correspondence to: U. Frieß (udo.friess@iup.uni-heidelberg.de)

Received: 19 November 2015 - Published in Atmos. Meas. Tech. Discuss.: 15 January 2016

Revised: 20 June 2016 - Accepted: 6 July 2016 - Published: 22 July 2016

\begin{abstract}
A first direct intercomparison of aerosol vertical profiles from Multi-Axis Differential Optical Absorption Spectroscopy (MAX-DOAS) observations, performed during the Cabauw Intercomparison Campaign of Nitrogen Dioxide measuring Instruments (CINDI) in summer 2009, is presented. Five out of 14 participants of the CINDI campaign reported aerosol extinction profiles and aerosol optical thickness (AOT) as deduced from observations of differential slant column densities of the oxygen collision complex $\left(\mathrm{O}_{4}\right)$ at different elevation angles. Aerosol extinction vertical profiles and AOT are compared to backscatter profiles from a ceilometer instrument and to sun photometer measurements, respectively. Furthermore, the near-surface aerosol extinction coefficient is compared to in situ measurements of a humidity-controlled nephelometer and dry aerosol absorption measurements. The participants of this intercomparison exercise use different approaches for the retrieval of aerosol information, including the retrieval of the full vertical profile using optimal estimation and a parametrised approach with a prescribed profile shape. Despite these large conceptual differences, and also differences in the wavelength of
\end{abstract}

the observed $\mathrm{O}_{4}$ absorption band, good agreement in terms of the vertical structure of aerosols within the boundary layer is achieved between the aerosol extinction profiles retrieved by the different groups and the backscatter profiles observed by the ceilometer instrument. AOTs from MAX-DOAS and sun photometer show a good correlation $(R>0.8)$, but all participants systematically underestimate the AOT. Substantial differences between the near-surface aerosol extinction from MAX-DOAS and from the humidified nephelometer remain largely unresolved.

\section{Introduction}

Aerosols play an important role in the atmospheric system. Aerosol particles scatter and absorb radiation but also affect the formation, optical properties, and lifetime of clouds and therefore have an impact on the radiation balance of the Earth's atmosphere. However, the impact of aerosols on the climate system is still only poorly understood (Stocker et al., 2013). Direct emission of soot particles, as well the forma- 
tion of secondary organic aerosols and the condensation of atmospheric gases on aerosol particles (e.g., sulfuric acid or organic vapours), affect air quality and human health. Various chemical processes in the atmosphere can be strongly affected by aerosols, since these provide surfaces for heterogeneous reactions. Examples are the heterogeneous formation of nitrous acid on soot particles (Ammann et al., 1998), the autocatalytic release of reactive bromine on sea salt aerosols in polar regions (Simpson et al., 2007), and the stratospheric ozone depletion as a consequence of halogen activation on polar stratospheric clouds (Crutzen and Arnold, 1986).

A quantification of the optical properties, spatial distribution, and chemical composition of aerosols is crucial for an understanding of these processes. Therefore, measurement techniques for the determination of the amount, vertical distribution, and optical properties of aerosols using relatively simple and cost-effective instrumentation are highly desirable. Furthermore, knowledge on the spatial distribution of aerosols and their impact on the radiative transfer is also important for the interpretation of passive atmospheric remote sensing observations from ground and satellite. MultiAxis Differential Optical Absorption Spectroscopy (MAXDOAS) measurements allow for the retrieval of aerosol extinction profiles, and are sensitive to aerosol microphysical and optical properties, in the planetary boundary layer. The usage of MAX-DOAS measurements for the retrieval of atmospheric aerosol properties (Hönninger et al., 2004; Wagner et al., 2004; Frieß et al., 2006) has found a growing number of applications during recent years (e.g., Irie et al., 2008, 2009; Lee et al., 2009; Takashima et al., 2009; Clémer et al., 2010; Li et al., 2010; Vlemmix et al., 2010; Zieger et al., 2011; Frieß et al., 2011; Wagner et al., 2011; Sinreich et al., 2013; Wang et al., 2014; Hendrick et al., 2014; Vlemmix et al., 2015).

As part of these studies, MAX-DOAS aerosol profiles, aerosol optical thickness (AOT), and/or surface extinction were compared to established instrumentation, such as lidar, sun photometer, and in situ aerosol instruments. These intercomparison studies are of great value for the validation of MAX-DOAS aerosol retrievals but suffer from several difficulties. A comparison of the AOT from MAX-DOAS and sun photometer does not allow for a validation of the retrieved profile shape. Compared to lidar profiles, MAX-DOAS has a much coarser vertical resolution and a different altitude sensitivity. Backscatter lidar instruments only provide information on the backscatter signal, and a determination of the actual aerosol extinction from these measurements is subject to large uncertainties. Therefore comparisons of backscatter lidar with MAX-DOAS extinction profiles can generally only be performed on a qualitative basis. Raman lidar systems can directly measure aerosol extinction profiles but suffer from a low signal-to-noise ratio during daylight, while MAX-DOAS measurements cannot be performed at night. A further shortcoming of lidar measurements is the limited overlap between lidar beam and field of view of the receiv- ing telescope which leads to a lack of reliable data near the surface where MAX-DOAS is most sensitive. A comparison of MAX-DOAS measurements with in situ instrumentation, such as nephelometer and Multi-Angle Absorption Photometer (MAAP), is complicated by the fact that in situ instruments perform point-like measurements, usually directly at or near the surface, whereas the aerosol surface extinction from MAX-DOAS represents an average over a certain height range with a typical vertical extent of $50-100 \mathrm{~m}$. For this study, these complications are partly overcome by using a common aerosol inlet at $60 \mathrm{~m}$ above ground. The in situ aerosol measurements are therefore expected to be more comparable to the MAX-DOAS observations than for an inlet directly at the surface. Most aerosol in situ instruments measure quantities which are not directly comparable to MAX-DOAS. Aerosols can take up water and therefore their optical properties - especially the particle light scattering coefficient - strongly depend on the ambient relative humidity (RH) (Zieger et al., 2013). Continuous groundbased measurements by nephelometer instruments are usually performed on dried air samples. Here a RH-controlled nephelometer is used to retrieve the ambient value in addition to dry particle light absorption measurements (FierzSchmidhauser et al., 2010; Zieger et al., 2011). A general problem of comparisons between remote sensing and in situ observations is that MAX-DOAS usually measures different air masses, with the retrieved aerosol profiles being representative for an average over the light paths in the lowermost troposphere that extend horizontally over several kilometres.

Here we present first direct intercomparisons of aerosol extinction profiles retrieved using MAX-DOAS measurements and aerosol retrieval algorithms from several groups. The measurements were performed in the framework of the Cabauw Intercomparison Campaign of Nitrogen Dioxide measuring Instruments (CINDI) at the Cabauw Experimental Site for Atmospheric Research (CESAR) in the Netherlands $\left(51.97^{\circ} \mathrm{N}, 4.93^{\circ} \mathrm{E}\right)$, during June/July 2009 . An overview of the campaign as well as details of the instrumentation and DOAS data analysis can be found in Piters et al. (2012) and Roscoe et al. (2010). In total, 22 instruments from 14 institutes participated in the campaign, of which five participants delivered data on the aerosol vertical distribution or on AOT. During CINDI, MAX-DOAS measurements were performed continuously by all instruments in a west-north-westerly direction (around $287^{\circ}$ azimuth angle). The nominal set of elevation angles included 90,30, 15, 8, 4 , and $2^{\circ}$, but some instruments also observed skylight from additional directions. A primary objective of CINDI was the intercomparison of the differential slant column densities (dSCDs) of $\mathrm{NO}_{2}$ and the oxygen collision complex $\mathrm{O}_{4}$ measured by MAX-DOAS. A previous study has demonstrated that the $\mathrm{O}_{4} \mathrm{dSCDs}$ from the different instruments participating in the CINDI campaign, which serve as input for the aerosol retrieval algorithms, show good agreement (Roscoe et al., 2010). Therefore, a comparison of aerosol properties derived from the 
measured $\mathrm{O}_{4}$ dSCDs allows us to investigate differences in the various retrieval algorithms, which use a variety of different approaches, as well as the choice of different retrieval parameters (e.g., the a priori).

\section{Retrieval of atmospheric aerosol properties from MAX-DOAS}

MAX-DOAS measurements of scattered sunlight yield dSCDs, i.e. the difference $\mathrm{d} S(\alpha)=S(\alpha)-S_{\text {ref }}$ between the slant column density of atmospheric trace gases measured at an elevation angle $\alpha$ (angle between the horizon and the line of sight, LOS) and a reference measurement $S_{\text {ref. For }}$ aerosol and trace gas retrievals, usually a zenith sky measurement of the same elevation sequence, i.e. closest in time to the off-axis measurements, is chosen as reference. The slant column density represents the integrated trace gas concentration along the light path, $S=\int \rho(s) \mathrm{d} s$, with the integral representing the weighted average over individual light paths through the atmosphere. The oxygen collision complex $\mathrm{O}_{4}$ exhibits pronounced absorption structures in the UV/vis spectral region (Greenblatt et al., 1990). Since its concentration is proportional to the square of the $\mathrm{O}_{2}$ concentration, which is well known, variations in the $\mathrm{O}_{4}$ dSCDs are caused by variations in the atmospheric light path, which is altered by the presence of aerosols. Therefore, measurements of the oxygen collision complex $\mathrm{O}_{4}$ at different LOS allow for the retrieval of atmospheric aerosol properties. Alternatively, or in addition to the $\mathrm{O}_{4} \mathrm{dSCDs}$, relative intensities, i.e. the ratio of the detector signal measured in the zenith and in off-axis directions, can be used to retrieve atmospheric aerosol properties (Frieß et al., 2006).

Since MAX-DOAS measurements only contain indirect information on the aerosol vertical profile, inverse methods are necessary for the retrieval procedure (Frieß et al., 2006). In general, aerosol properties are derived by comparing the measured $\mathrm{O}_{4} \mathrm{dSCDs}$ (and/or relative intensities) at different elevation angles to simulations from radiative transfer models (RTMs). Using nonlinear inversion algorithms, the aerosol properties that serve as input for the RTM are altered until best agreement between measurement and simulation is achieved. A general problem that MAX-DOAS has in common with other atmospheric remote sensing techniques is the limited information content of the measurements. As a consequence, the full state vector (e.g., an aerosol extinction profile $k(z)$ at high vertical resolution) cannot be reconstructed without any further constraints to the results. Here, different approaches are possible: either a Bayesian approach is applied where additional constraints are posed in the form of an a priori state vector or a parametrisation with only a small number of quantities describing the aerosol vertical distribution (e.g., the AOT or the layer height and AOT of a box profile) is used. The solution of the former approach is retrieved using the well-known optimal estimation method
(OEM) (Rodgers, 2000), whereas the latter approach is based on more simple least-squares methods (LSMs). In general, the solution of the inverse problem $\hat{\boldsymbol{x}}$ is determined by minimising a cost function in the form of

$$
\begin{aligned}
\chi^{2} & =(\boldsymbol{y}-\mathbf{F}(\boldsymbol{x}, \boldsymbol{b}))^{T} \mathbf{S}_{\epsilon}^{-1}(\boldsymbol{y}-\mathbf{F}(\boldsymbol{x}, \boldsymbol{b})) \\
& +\left(\boldsymbol{x}-\boldsymbol{x}_{\mathrm{a}}\right)^{T} \mathbf{S}_{\mathrm{a}}^{-1}\left(\boldsymbol{x}-\boldsymbol{x}_{\mathrm{a}}\right) .
\end{aligned}
$$

$\mathbf{F}(\boldsymbol{x}, \boldsymbol{b})$ is a forward model (here an RTM), which describes the measurement $\boldsymbol{y}$ (the $\mathrm{O}_{4}$ dSCDs and/or relative intensities) as a function of the atmospheric state $\boldsymbol{x}$ (the aerosol vertical profile). The vector $\boldsymbol{b}$ represents additional forward model parameters (e.g. aerosol single scattering albedo (SSA) and phase function) which are not retrieved. In the case of OEM algorithms, the a priori state vector $\boldsymbol{x}_{\mathrm{a}}$ with covariance $S_{a}$ serves as an additional constraint, which has to be considered because the information content of the measurement is usually too low to allow for a full reconstruction of the atmospheric state on the basis of the measurements only. In the case of LSMs, the a priori information represented by the second term in Eq. (1) is omitted (i.e., $\mathbf{S}_{\mathrm{a}}^{-1} \equiv 0$ ), and only a small number of parameters (i.e., layer height and AOT) are retrieved. The covariance matrix $\mathbf{S}_{\epsilon}$ describes the uncertainties in the measurement (in the case of LSMs sometimes set to unity when no error weighting is performed). The vertical resolution of the retrieval is quantified by the so-called averaging kernel matrix $\mathbf{A}=\partial \hat{\boldsymbol{x}} / \partial \boldsymbol{x}$, which represents the sensitivity of the retrieved profile as a function of the true atmospheric profile. The retrieved profile $\hat{\boldsymbol{x}}$ can be represented as the true profile $\boldsymbol{x}$, smoothed by the averaging kernel matrix A according to

$\hat{\boldsymbol{x}}=\boldsymbol{x}_{\mathrm{a}}+\mathbf{A}\left(\boldsymbol{x}-\boldsymbol{x}_{\mathrm{a}}\right)$.

The general features of the different algorithms participating in the intercomparison are summarised in Table 1, and the individual retrieval algorithms are briefly described in the following sections. $\mathrm{O}_{4} \mathrm{dSCDs}$ or relative intensities measured at several elevation angles, relative to a zenith sky spectrum of the same sequence, serve as input measurement vector. Some participants (Heidelberg and JAMSTEC) do not use single elevation sequences but rather all observations within a fixed time period (20 and $30 \mathrm{~min}$, respectively) as input vector. All participants except the Max Planck Institute for Chemistry (MPIC) use OEM algorithms for the retrieval. MPIC uses an LSM algorithm for the retrieval of AOT and aerosol layer height (see Sect. 2.4). For the intercomparison, a reference wavelength of $477 \mathrm{~nm}$ has been chosen since most of the participants use the $\mathrm{O}_{4}$ absorption band at this wavelength for the aerosol retrieval. Aerosol properties measured at other wavelengths (retrievals from MPIC, as well as ceilometer, sun photometer, and humidified nephelometer) are converted to $477 \mathrm{~nm}$ using the Ångström coefficient $\alpha$ derived from co-located sun photometer measurements at 
Table 1. Main features of the different retrieval algorithms.

\begin{tabular}{|c|c|c|c|c|c|c|c|}
\hline Participant & Method $^{1}$ & Measurement & Wavelength & Retrieved quantities & Vertical grid & Sampling interval & $\begin{array}{l}\mathrm{O}_{4} \text { correction } \\
\text { factor }\end{array}$ \\
\hline AIOFM & OEM & $\mathrm{O}_{4}$ and intensity & $477 \mathrm{~nm}$ & Extinction profile & $200 \mathrm{~m}$ & $\approx 7 \min$ & 0.8 \\
\hline BIRA & OEM & $\mathrm{O}_{4} \mathrm{dSCDs}$ & $477 \mathrm{~nm}$ & Extinction profile & $200 \mathrm{~m}$ & $\approx 20 \mathrm{~min}$ & 0.8 \\
\hline Heidelberg & OEM & $\mathrm{O}_{4} \mathrm{dSCDs}$ & $477 \mathrm{~nm}$ & Extinction profile & $200 \mathrm{~m}$ & $20 \mathrm{~min}$ & 1.0 \\
\hline JAMSTEC & OEM & $\mathrm{O}_{4} \mathrm{dSCDs}$ & $477 \mathrm{~nm}$ & Extinction profile & $1000 \mathrm{~m}$ & $30 \mathrm{~min}$ & variable $^{2}$ \\
\hline MPIC & LSM & $\mathrm{O}_{4} \mathrm{dSCDs}$ & $360 \mathrm{~nm}$ & Layer height \& AOT & $\mathrm{n} / \mathrm{a}$ & $\approx 15 \min$ & 0.77 \\
\hline
\end{tabular}

1 OEM: optimal estimation method; LSM: least-squares method

2 see Irie et al. (2011)

wavelengths of 440 and $675 \mathrm{~nm}$. In contrast to all other retrieval algorithms, the Anhui Institute of Optics and Fine Mechanics (AIOFM) uses observed relative intensities in addition to $\mathrm{O}_{4}$ dSCDs as input vector (for details see Sect. 2.5). Furthermore, AIOFM did not participate in the CINDI campaign with their own instrument but rather use data measured by the Heidelberg instrument as input for their own retrieval algorithm.

The a priori profiles for the BIRA, Heidelberg, AIOFM and JAMSTEC retrievals are shown in Fig. 1. Heidelberg and AIOFM use similar a priori profiles with an aerosol extinction at the surface of 0.1 and $0.08 \mathrm{~km}^{-1}$, respectively, and a linear decrease with altitude. The BIRA algorithm assumes a significantly smaller a priori aerosol extinction, with a surface value of $0.05 \mathrm{~km}^{-1}$ and an exponential decrease with altitude. The JAMSTEC algorithm represents the aerosol profile on a much coarser vertical grid than the other algorithms using three layers of $1 \mathrm{~km}$ thickness each and assumes a larger a priori extinction with a value of $0.126 \mathrm{~km}^{-1}$ in the lowermost layer. More specific information on the choice of the a priori profiles and the a priori covariance matrices can be found in the following sections. Depending on the information content of the measurements, or more specifically the values of the averaging kernels in each layer, there will be a potential bias of the retrieved aerosol extinction profiles towards the a priori profiles (see Eq. 2). This influence of the a priori profile on the resulting extinction profiles needs to be considered when comparing the results from the different retrieval algorithms.

Based on aerosol profiles scaled by the AOT of a colocated sun photometer, it has been found by Clémer et al. (2010) that measured $\mathrm{O}_{4}$ dSCDs are significantly lower than simulated dSCDs, and it was suggested to multiply the measured dSCDs with a constant scaling factor of 0.8 prior to the retrieval to resolve this disagreement. The observed discrepancy is potentially caused by uncertainties in the absolute value of the $\mathrm{O}_{4}$ cross section, possibly owing to a limited knowledge of the temperature dependence of the absorption strength. However, a recent study by Spinei et al. (2015) on the basis of direct sunlight DOAS measurements indicates that measured $\mathrm{O}_{4}$ DSCDs are in very good agreement with theoretically expected values without applying any correc-

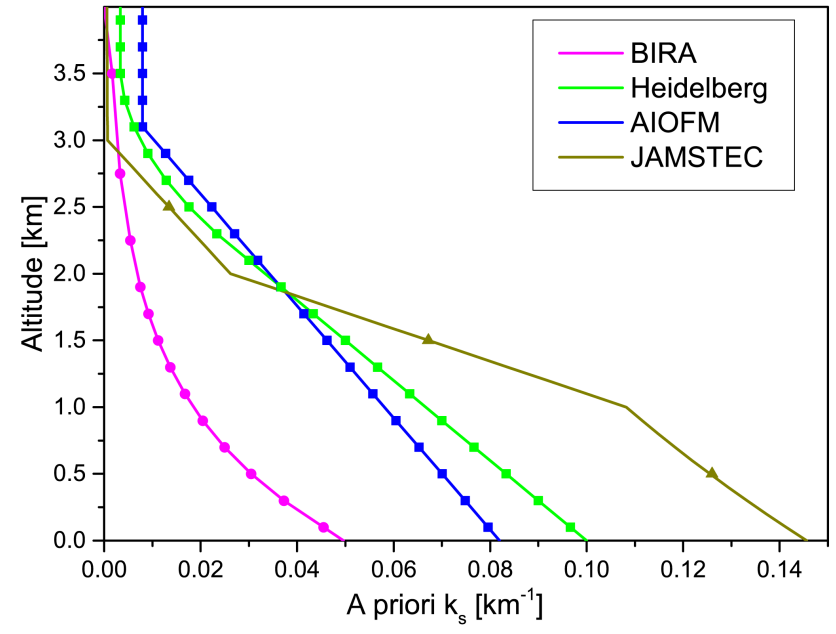

Figure 1. A priori profiles for the BIRA, Heidelberg, AIOFM, and JAMSTEC retrievals. The symbols indicate the centre of each retrieval layer. The BIRA, Heidelberg, and AIOFM algorithms use a $200 \mathrm{~m}$ vertical grid with constant extinction in each layer, and JAMSTEC a $1 \mathrm{~km}$ grid with exponentially decreasing extinction in each layer.

tion factor, and Ortega et al. (2016) suggest that elevated aerosol layers might cause the observed discrepancies. The different correction factors applied to the $\mathrm{O}_{4} \mathrm{dSCDs}$ in the present study are listed in Table 1 . The values correspond to what the individual groups consider as their "best setting". BIRA and AIOFM apply a correction factor of 0.8 , MPIC a factor of 0.77 , and JAMSTEC has implemented a variable correction factor which is part of the state vector and is retrieved by their algorithm (for details see Irie et al., 2011).

\subsection{The BIRA retrieval algorithm}

The BIRA-IASB OEM-based profiling tool called bePRO is extensively described in Clémer et al. (2010) and Hendrick et al. (2014). The forward model is the linearised discrete ordinate radiative transfer (LIDORT) model (Spurr, 2008). The LIDORT code includes an analytical calculation in a pseudospherical geometry of the weighting functions needed for the profile inversion. This allows for near-real-time automated 
retrievals of aerosol and trace gas vertical distributions without the use of pre-calculated lookup tables. The standard vertical grid implemented in bePRO consists of 10 layers of $200 \mathrm{~m}$ thickness between 0 and $2 \mathrm{~km}, 2$ layers of $500 \mathrm{~m}$ between 2 and $3 \mathrm{~km}$, and 1 layer between 3 and $4 \mathrm{~km}$ altitude. Pressure and temperature profiles are taken from the Air Force Geophysics Laboratory (AFGL) database. For each scan, the $\mathrm{O}_{4}$ dSCDs measured at $477 \mathrm{~nm}$ at nine elevation angles $\left(1,2,3,4,5,8,10,15\right.$, and $30^{\circ}$ serve as the measurement vector $\boldsymbol{y}$. The corresponding $\mathbf{S}_{\epsilon}$ matrix is constructed as a diagonal matrix, with variances equal to the square of the $\mathrm{O}_{4}$ DOAS fitting error. A correction factor of 0.8 has been applied to the dSCDs (Clémer et al., 2010). An exponentially decreasing aerosol extinction profile with an AOT of 0.05 and a scaling height of $1 \mathrm{~km}$ is used as a priori. The a priori error covariance matrix is set as in Clémer et al. (2010): the diagonal element corresponding to the lowest layer, $\mathbf{S}_{\mathrm{a}}(1,1)$, is equal to the square of a scaling factor $\beta$ ( $\beta=0.1$ in the present case) times the maximum partial AOT of the profile. The other diagonal elements decrease linearly with altitude down to $0.2 \cdot \mathbf{S}_{\mathrm{a}}(1,1)$. The off-diagonal terms in $\mathbf{S}_{\mathrm{a}}$ are set using Gaussian functions with a correlation length of $50 \mathrm{~m}$. The aerosol SSA and phase functions needed for the weighting functions calculations are derived offline based on the colocated AErosol RObotic NETwork (AERONET) sun photometer measurements. The surface albedo is fixed to $7 \%$.

\subsection{The Heidelberg retrieval algorithm}

The HeiPro retrieval is an updated version of the algorithm already described in detail in Frieß et al. (2006) and Frieß et al. (2011). It is based on the optimal estimation method and retrieves the most probable state vector by minimising the cost function given by Eq. (1). The radiative transfer model SCIATRAN (Rozanov et al., 2005a) serves as forward model for the retrieval. The state vector $\boldsymbol{x}$ consists of the logarithm of the extinction in 20 layers of $200 \mathrm{~m}$ thickness, extending from the surface up to $4 \mathrm{~km}$ altitude. Using the logarithm of the extinction instead of the actual extinction has the advantage that negative values are avoided, which cannot be processed by the RTM. The $\mathrm{O}_{4}$ dSCDs measured at $477 \mathrm{~nm}$ at elevation angles of $30,15,8,4$, and $2^{\circ}$ serve as the measurement vector $\boldsymbol{y}$, and the diagonal values of the measurement covariance matrix $\mathbf{S}_{\epsilon}$ are set to the square of the dSCD measurement errors. In contrast to the other groups, no correction factor was applied to the dSCDs prior to the retrieval with the HeiPro algorithm. All measurements within a fixed time interval of 20 min serve as measurement vector. Given a measurement time of about $7 \mathrm{~min}$ for a single elevation sequence, this means that the measurement vector usually contains several measurements at the same elevation angle. The a priori has an extinction of $0.1 \mathrm{~km}^{-1}$ at the surface, is linearly decreasing from the surface up to an altitude of $3.5 \mathrm{~km}$, and is constant above this with a value of $0.0033 \mathrm{~km}^{-1}$. This a priori profile has been smoothed with a seven-point running average. The a priori error (square root of the diagonal elements of $\mathbf{S}_{\mathrm{a}}$ ) has been set to $100 \%$ of the a priori at all altitudes, and the non-diagonal elements of $\mathbf{S}_{\mathrm{a}}$ are exponentially decreasing with distance between layer altitudes with a correlation length of $1 \mathrm{~km}$. For the radiative transfer calculations, aerosol SSA, and asymmetry parameter $g$ were adapted from the co-located AERONET sun photometer measurements. For this intercomparison, all profiles retrieved by the Heidelberg groups were used without any further quality filtering of the data.

\subsection{The JAMSTEC retrieval algorithm}

The Japanese MAX-DOAS profile retrieval algorithm version 1 (JM1) applied to MAX-DOAS observations of $\mathrm{O}_{4}$ at elevation angles of $2,4,8,15$, and $30^{\circ}$ performed by JAMSTEC is described in detail in Irie et al. (2011). It is based on the optimal estimation method to solve the nonlinear inversion problem. The state vector consists of AOT and three parameters determining the shape of the vertical profile. An advantage of this parametrisation is that the absolute value of the aerosol extinction is unnecessary in the state vector. Instead, a priori knowledge of the profile shape is needed. The aerosol extinction is given as the product of the AOT and profile shape but the aerosol extinction retrieval is less subject to a prior knowledge of the AOT and profile shape as the resulting a priori error for the aerosol extinction is large. The adopted parametrisation primarily yields partial AOT values or mean aerosol extinction values for layers of $0-1,1-2,2-$ 3 , and $3-100 \mathrm{~km}$. Since a vertical profile shape within each layer is considered, extraction of aerosol extinction coefficients at any altitude is possible (Irie et al., 2008). A lookup table of the box-air-mass-factor vertical profile used in the forward model was created using the JACOSPAR RTM, which was developed based on its predecessor MCARaTS (the Monte Carlo Atmospheric Radiative Transfer Simulator; Iwabuchi, 2006). Parameters for the JAMSTEC retrieval were 0.95 for the single scattering albedo, 0.65 for the asymmetry parameter (under the Henyey-Greenstein approximation), and 0.1 for the surface albedo. Instead of applying a constant correction factor to the measured $\mathrm{O}_{4}$ dSCDs, a variable correction factor is applied which is part of the state vector and thus retrieved by the algorithm (for further details see Irie et al., 2011).

\subsection{The MPIC retrieval algorithm}

The MPIC profile inversion is described in detail in Wagner et al. (2011). It is based on the comparison of the measured $\mathrm{O}_{4}$ absorption (analysed using the absorption bands at 360 and $380 \mathrm{~nm}$ in a joint fitting window ranging from 353 to $390 \mathrm{~nm}$ ) at elevation angles of $2,4,8,15$, and $30^{\circ}$ with simulated $\mathrm{O}_{4}$ differential air-mass factors (dAMFs). The retrieved $\mathrm{O}_{4}$ dSCDs are converted into dAMFs by dividing them by the atmospheric $\mathrm{O}_{4}$ vertical column density (VCD). From verti- 
cal profiles of temperature and pressure at Cabauw the $\mathrm{O}_{4}$ VCD was determined to $1.32 \times 10^{43} \mathrm{molec}^{2} \mathrm{~cm}^{-5}$ (for the units, see Greenblatt et al., 1990). Finally, the $\mathrm{O}_{4}$ dAMFs are scaled by a constant factor of 0.77 . The MPIC retrieval follows the method of $\mathrm{Li}$ et al. (2010) with slight modifications described in Wagner et al. (2011). Atmospheric $\mathrm{O}_{4}$ dAMFs are simulated using the radiative transfer model McARTIM (Deutschmann et al., 2011), assuming a large variety of atmospheric aerosol extinction profiles, which are described by a simple parametrisation scheme: for the CINDI campaign the total aerosol optical depth and the layer height were varied. The profile shape is composed of two parts: a box profile from the surface to the layer height with a constant aerosol extinction and an exponentially decreasing part above $(5 \%$ of the total AOT are contained in this exponentially decreasing part). From a least-squares fitting procedure between the measured and simulated $\mathrm{O}_{4}$ dAMFs, the total aerosol optical depth and layer height of the box profile are determined for each elevation sequence. The aerosol extinction is derived by dividing the AOT of the box profile (95\% of the total AOT) by the layer height. The errors of the retrieved profiles are assessed based on (a) the residual sum of squares between the measurement and the model results and (b) from the fit process itself, taking into account the sensitivity of the measured quantities with respect to variations of the profile parameters.

\subsection{The AIOFM retrieval algorithm}

The "Profile inversion algorithm of aerosol extinction and trace gas concentration developed at AIOFM in cooperation with MPIC" (PriAM) (Wang et al., 2013) is applied to the $\mathrm{O}_{4}$ dSCDs and relative intensities from Heidelberg MAX-DOAS instrument at elevation angles of 2, 4, 8, 15 , and $30^{\circ}$ to retrieve profiles of aerosol extinction. The PriAM algorithm is based on the optimal estimation method (Rodgers, 2000) and implements a nonlinear iterative approach which is based on the Gauss-Newton method modified by Levenberg-Marquardt to speed up the minimisation of the cost function. The measurement vector $\boldsymbol{y}$ consists of the $\mathrm{O}_{4}$ dSCDs and relative intensities at $477 \mathrm{~nm}$ in each measurement sequence. The measured $\mathrm{O}_{4} \mathrm{dSCDs}$ are scaled down by a factor of 0.8 . Including relative intensities is a strong constraint for the AOT and improve the sensitivity of the inversion on the upper layers (Frieß et al., 2006). The a priori profile $\boldsymbol{x}_{\mathrm{a}}$ is a linear decreasing profile with an AOT of 0.15 . A priori uncertainty covariance matrix $\mathbf{S}_{\mathrm{a}}$ is nondiagonal with the diagonal elements of the square of $33 \%$ of $\boldsymbol{x}_{\mathrm{a}}$ and non-diagonal elements calculated from the Gaussian function with the correlation length of $0.5 \mathrm{~km}$ (Frieß et al., 2006). A diagonal measurement uncertainty covariance matrix $\mathbf{S}_{\epsilon}$ has the diagonal elements of the square of $100 \%$ fitting errors of the $\mathrm{O}_{4} \mathrm{dSCDs}$ and $1.5 \%$ of the relative intensities. Due to the deviation of the true aerosol phase function from the Henyey-Greenstein parametrisation (Henyey and Greenstein, 1941) used in the model simulations (Wang et al., 2015) for the forward scattering, artifacts occur in the retrieved aerosol profiles at small relative azimuth angles when including intensity. Considering this effect, the error of the intensity has been increased from 1.5 to $3 \%$ in the afternoon. This effectively decreases the weight of the information from relative intensities compared to the information from $\mathrm{O}_{4}$ dSCDs. For the measurements on 1 and 2 July, the relative intensity has been excluded from the retrieval for relative azimuth angles below $20^{\circ}$. The weighting function $\mathbf{K}$ is calculated using the full-spherical RTM SCIATRAN 2.2 (Rozanov et al., 2005b).

\subsection{Complementary measurements}

A large variety of aerosol measurements, both in situ and by remote sensing, were performed during the CINDI campaign: backscatter and Raman lidar systems as well as a ceilometer measured the vertical distribution of aerosol in terms of backscatter and extinction profiles; two nephelometer systems, one of which was humidity controlled, and a multi-angle absorption photometer measured the scattering and absorption properties of aerosol particles; finally, a sun photometer measured the AOT.

Backscatter profiles measured by a Vaisala LD40 ceilometer regularly operated at the CESAR site by KNMI are used for the validation of the aerosol profiles retrieved from MAXDOAS. The ceilometer has a vertical resolution of $30 \mathrm{~m}$ and measures backscatter profiles every $30 \mathrm{~s}$ at a wavelength of $905 \mathrm{~nm}$ from about $120 \mathrm{~m}$ up to $11.5 \mathrm{~km}$ altitude using a pulsed InGaAs laser diode. Due to the limited overlap between outgoing laser beam and the field of view of the collecting telescope, no valid backscatter data are available for altitudes below $120 \mathrm{~m}$.

The AOT at $440,675,870$, and $1020 \mathrm{~nm}$, as well as the corresponding Ångström parameters, SSA, and phase function, are retrieved from continuous measurements at the CESAR site by an automated CIMEL CE 318 sun photometer using direct sunlight measurements. This instrument, operated by TNO, is part of the AERONET. A summary of the AERONET Level 2 data during the "golden days" of CINDI campaign, which were characterised by predominantly clear sky conditions (see Sect. 3), is shown in Fig. 2. The AOT varies between 0.1 and 0.7 , with a mean and standard deviation of 0.34 and 0.18 , respectively. The Ångström exponent, which describes the wavelength dependence of the aerosol extinction, is $1.49 \pm 0.14$. The aerosol SSA during CINDI is significantly lower than at other urban sites (Dubovik et al., 2002), with values as low as 0.84 at the beginning of the campaign and a mean value of $0.92 \pm 0.03$, indicating that significant amounts of absorbing particles are present. Furthermore, a mean asymmetry parameter of $0.72 \pm 0.02$ has been retrieved from sun photometer measurements.

The aerosol scattering coefficient $k_{\mathrm{s}}$ near the surface was determined by a humidified nephelometer (WetNeph) in combination with a simultaneously operated dry-air neph- 


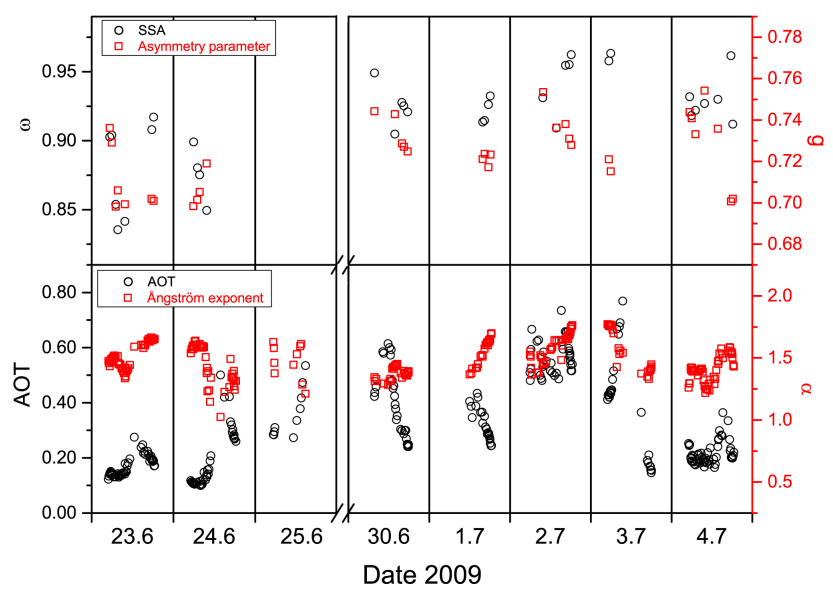

Figure 2. Summary of the AERONET data obtained during the golden days of the CINDI campaign. Top: single scattering albedo $\omega$ and asymmetry parameter $g$ at $441 \mathrm{~nm}$ from almucantar measurements. Bottom: AOT at $440 \mathrm{~nm}$ and Ångström coefficient $\alpha$ retrieved from direct sunlight measurements at 440 and $675 \mathrm{~nm}$.

elometer. The WetNeph is described in detail by FierzSchmidhauser et al. (2010), and a comparison of extinction coefficients from MAX-DOAS and WetNeph has already been described in Zieger et al. (2011). Briefly, the aerosol scattering coefficient $k_{\mathrm{S}}$ as well as the back scattering coefficient $k_{\mathrm{b}}$ are measured at three wavelengths $(450,550$, and $700 \mathrm{~nm}$ ) at defined relative humidities between 20 and $95 \%$ using an integrating nephelometer (TSI Inc., model 3563). The WetNeph measurements allow the determination of the ambient particle extinction coefficient, assuming that the particle absorption coefficient does not change with RH. The ambient particle extinction coefficient can then be directly compared to the retrieved value of the MAX-DOAS without any further assumption on particle growth in humid air. The ambient RH measurements were taken at six different locations on the $200 \mathrm{~m}$ high mast. The inlet of the WetNeph was located at a height of $60 \mathrm{~m}$ at the Cabauw tower.

\section{Results}

In this section, quantities derived from the different aerosol retrieval algorithms are validated against independent measurements. Aerosol extinction profiles are compared to ceilometer measurements in Sect. 3.1. The comparison of retrieved AOT and surface extinction with data from sun photometer and in situ aerosol observations, respectively, is discussed in Sect. 3.2. For the comparison, 8 days with predominantly clear sky conditions ("golden days") were selected. These were 23-25 June and 30 June to 4 July 2009.

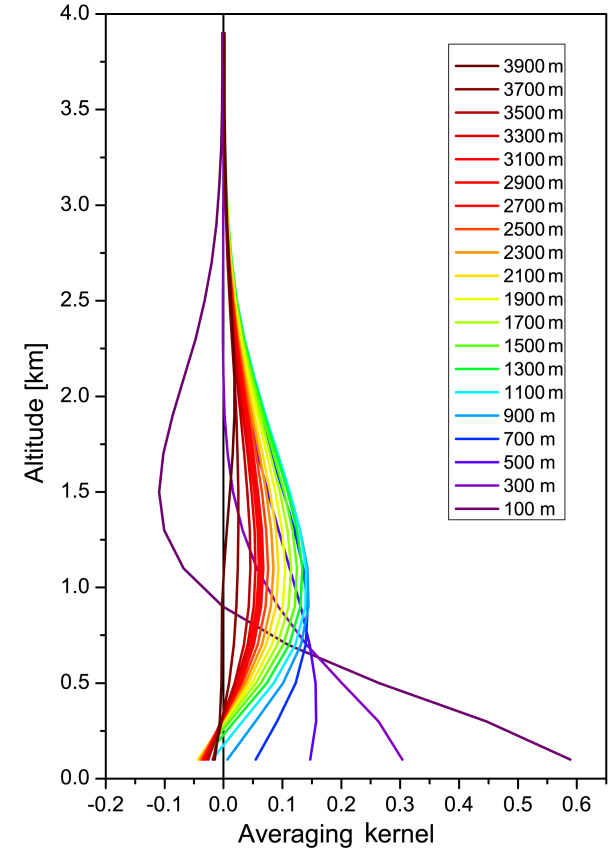

Figure 3. Example for aerosol extinction averaging kernels from the Heidelberg retrieval algorithm for 2 July 2009, 12:00 UTC.

\subsection{Comparison of aerosol vertical profiles}

In order to assess the ability of the different retrieval algorithms to determine the general structure of the boundary layer, aerosol vertical profiles are compared to backscatter profiles from a co-located ceilometer instrument. For this comparison, it is important to consider that MAX-DOAS measurements have a relatively low information content. The number of independent pieces of information from the measurement, quantified by the degrees of freedom for signal (DFS), typically ranges between 1 and 2. An example for aerosol extinction averaging kernels, taken from the Heidelberg retrieval, is shown in Fig. 3. The averaging kernels indicate that information on the extinction profile can be retrieved only for the lowermost $2 \mathrm{~km}$ of the atmosphere with highest sensitivity at the ground, where the vertical resolution (quantified by the altitude where the averaging kernel of the lowermost layer is half of its surface value) is $\approx 500 \mathrm{~m}$. The DFS strongly varies with visibility and is also a function of solar zenith angle (and to a smaller extent SSA); it is 1.9 for the example in Fig. 3.

Since the ceilometer backscatter profiles are characterised by a much higher vertical and temporal resolution than MAX-DOAS measurements, $20 \mathrm{~min}$ averages of the ceilometer profiles were degraded to the sensitivity of the Heidelberg MAX-DOAS profiles according to the method described by Rodgers and Connor (2003). The degraded backscatter profile $\boldsymbol{x}^{\prime}=\mathbf{A} \cdot \boldsymbol{x}$, with $\mathbf{A}$ being the averaging kernel matrix and $\boldsymbol{x}$ the original backscatter profile in high 
resolution, represents the profile $\boldsymbol{x}^{\prime}$ that would have been retrieved with MAX-DOAS if the true profile were $x$. Note that the original equation from Rodgers and Connor (2003), $\boldsymbol{x}^{\prime}=$ $\boldsymbol{x}_{\mathrm{a}}+\mathbf{A} \cdot\left(\boldsymbol{x}-\boldsymbol{x}_{\mathrm{a}}\right)$, cannot be applied here since the backscatter profiles $\boldsymbol{x}$ and the a priori extinction profiles $\boldsymbol{x}_{\mathrm{a}}$ are measured in different physical units. The ceilometer data have been averaged to the vertical grid of the MAX-DOAS retrieval $(200 \mathrm{~m})$ prior to the convolution with the averaging kernel. No or only limited overlap between outgoing beam and field of view of the telescope of the ceilometer is present in the lowermost $120 \mathrm{~m}$. For this reason, ceilometer data between surface and $150 \mathrm{~m}$ altitude are set to a constant value equal to the signal at $150 \mathrm{~m}$ during the convolution process. Therefore the lowermost layer of the convolved ceilometer profiles is subject to large uncertainties when high gradients near the surface exist. It is important to note that ceilometer and MAX-DOAS instruments retrieve different quantities. The MAX-DOAS retrieval algorithms yield extinction profiles, whereas the backscatter profiles from the ceilometer cannot be directly converted to an extinction profile without further assumptions on the ratio between backscatter and extinction. This so-called lidar ratio is not known a priori and is a function of the size and optical properties of the particles, which vary with time and altitude. Therefore ceilometer and MAX-DOAS profiles can only be compared qualitatively in terms of the vertical structure of the boundary layer. Furthermore, the MAX-DOAS instruments average over a large horizontal distance of up to several tens of kilometres, whereas the ceilometer probes the atmosphere directly over the measurement site.

The MAX-DOAS extinction profiles from the different groups together with the ceilometer backscatter profiles for the golden days are shown in Figs. 4-7. Note that BIRA, Heidelberg, and AIOFM retrieve the aerosol extinction on a vertical grid of $200 \mathrm{~m}$, whereas JAMSTEC represents the profile on four layers of $1 \mathrm{~km}$ thickness each, and MPIC retrieves the height and AOT of a box profile with a constant extinction from the surface up to a certain altitude (as well as an exponentially decreasing profile above, which contains $5 \%$ of the AOT). The gaps in the datasets are caused by different quality filters applied by the different groups and by missing data around noon, when reference measurements were performed.

In general, the vertical structure of the aerosol profile in the boundary layer of all groups shows good agreement with the ceilometer backscatter profiles, in particular after these are degraded to the MAX-DOAS vertical resolution by convolution with the averaging kernel. The temporal variation of the MAX-DOAS profiles is in good agreement with the ceilometer data, and the height of the boundary layer is generally captured very well in qualitative terms.

23 and 24 June are characterised by a relatively low extinction $\left(<0.4 \mathrm{~km}^{-1}\right)$, with an increase both in boundary layer height and in extinction in the early afternoon. These features are captured well by all groups. An enhanced backscatter at $\approx 1.5 \mathrm{~km}$ altitude in the early afternoon of 23 June, probably due to clouds, is captured by the retrievals of BIRA, Heidelberg, AIOFM, and JAMSTEC, which show uplifted layers of enhanced extinction during this period (no data are reported for this period by MPIC). However, as a consequence of the limited information content of MAX-DOAS measurements, these layers are smeared out over a layer extending from $200 \mathrm{~m}$ to $1.2 \mathrm{~km}$. A similar situation with an uplifted aerosol layer in the early afternoon occurs on 25 June. After 06:00 UTC on 25 June, a cloud is observed by the ceilometer at an altitude of $\approx 2 \mathrm{~km}$, which is still visible after convolution with the averaging kernel. The finding that none of the MAX-DOAS retrievals captures this cloud might be due to the fact that it is localised directly over the measurement site, whereas the MAX-DOAS extinction profiles are representative for the atmosphere in a distance of several kilometres along the LOS. In fact, the Heidelberg and AIOFM profiles exhibit layers of enhanced extinction $\left(\approx 0.15 \mathrm{~km}^{-1}\right)$ between 0.5 and $2 \mathrm{~km}$ throughout the morning of 25 June, which probably correspond to the cloud layer observed by the ceilometer in zenith between 06:00 and 08:00.

As can be seen from the webcam images in Fig. 8 that foggy conditions prevailed during the mornings of 30 June and 1 July. The ceilometer backscatter profiles show that these thin fog layers with a vertical extent in the order of $100 \mathrm{~m}$ were initially located very close to the surface and then uplifted during the course of the morning. Note that the backscatter profiles smoothed with the MAX-DOAS averaging kernel do not show an enhanced extinction in the early morning of 30 June because the fog layer was located at altitudes below $150 \mathrm{~m}$ and was therefore not considered in the smoothing procedure. These foggy conditions allow for an investigation of the behaviour of the retrieval algorithms in the presence of a layer of high extinction at different altitudes. As shown in Fig. 9, the diurnal variation of the DFS in the presence of fog is similar to the clear sky case. An enhanced extinction in the morning due to fog is detected by all retrieval algorithms. However, the limited vertical resolution in the presence of fog leads to a strong overestimation of the vertical extent of the extinction layer. On 30 June, the fog layer present during the early morning hours is blurred over an altitude of $0.5 \mathrm{~km}$ by BIRA, MPIC, and AIOFM and $1 \mathrm{~km}$ by Heidelberg and JAMSTEC, respectively. On 1 July, the retrieved fog layer extends up to $1.3,1.8$, and $1-2 \mathrm{~km}$ for the BIRA, Heidelberg, and MPIC retrievals, respectively, whereas the fog layer detected by the ceilometer was located below $500 \mathrm{~m}$ until 09:00 UTC. The vertical profiles retrieved by BIRA, Heidelberg and AIOFM are, however, qualitatively in good agreement with the expected profile as given by the ceilometer profiles smoothed with the MAX-DOAS averaging kernels. None of the algorithms are able to reproduce the elevated extinction layers occurring after the uplift of the fog layers in the course of the mornings of 30 June and 1 July. This might be caused by the general enhancement in extinction throughout the boundary layer on these 2 days, which 

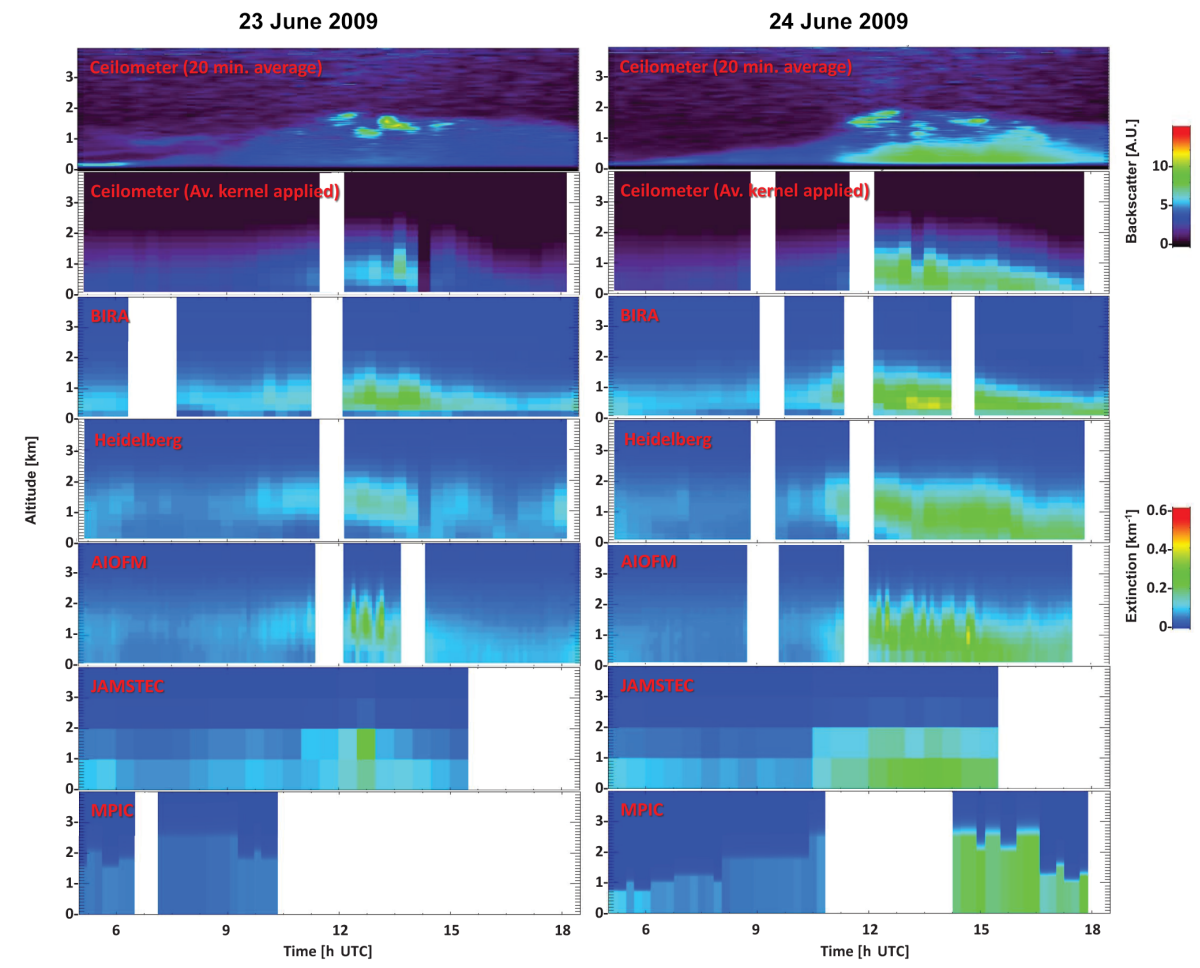

Figure 4. Comparison of MAX-DOAS extinction profiles with backscatter profiles from the ceilometer for 23 June (left) and 24 June (right). The top panel shows the backscatter signal in original vertical resolution, the second panel the backscatter signal with the averaging kernels of Heidelberg applied, and below that the extinction profiles retrieved from BIRA, Heidelberg, JAMSTEC, and MPIC. For MPIC box-profiles with the retrieved layer height and AOT are plotted.
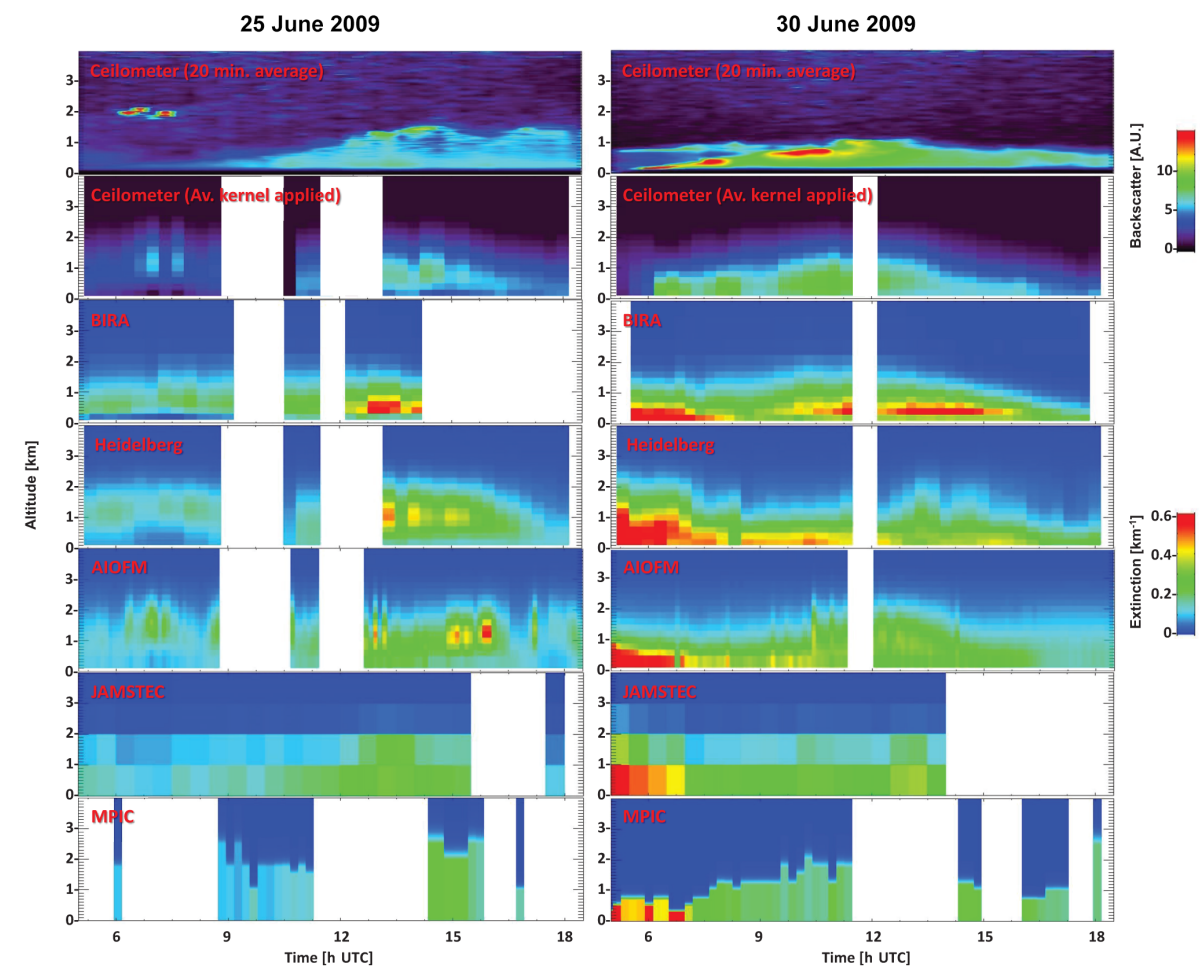

Figure 5. Same as Fig. 5 but for 25 June (left) and 30 June (right). 

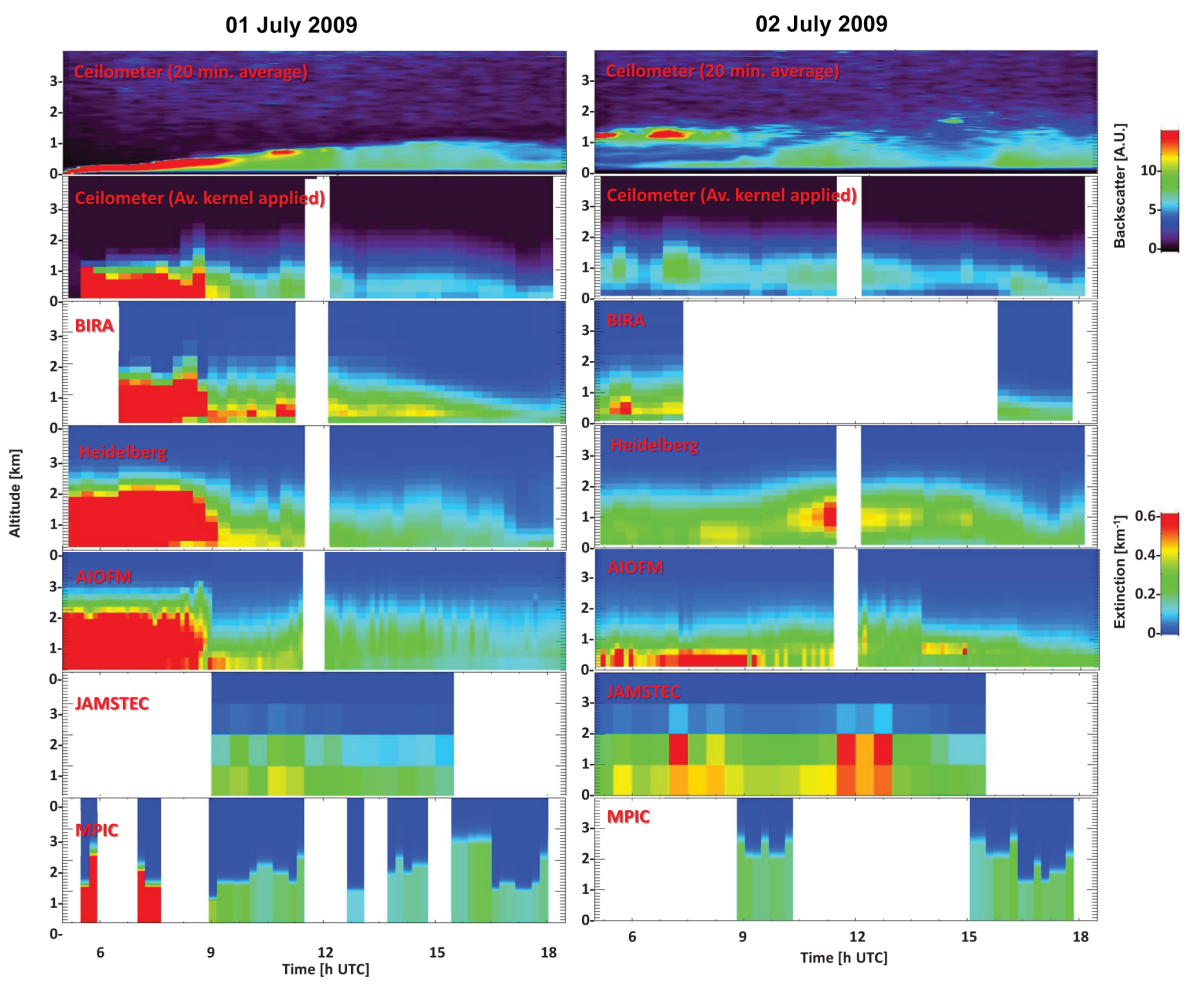

Figure 6. Same as Fig. 6 but for 1 July (left) and 2 July (right).
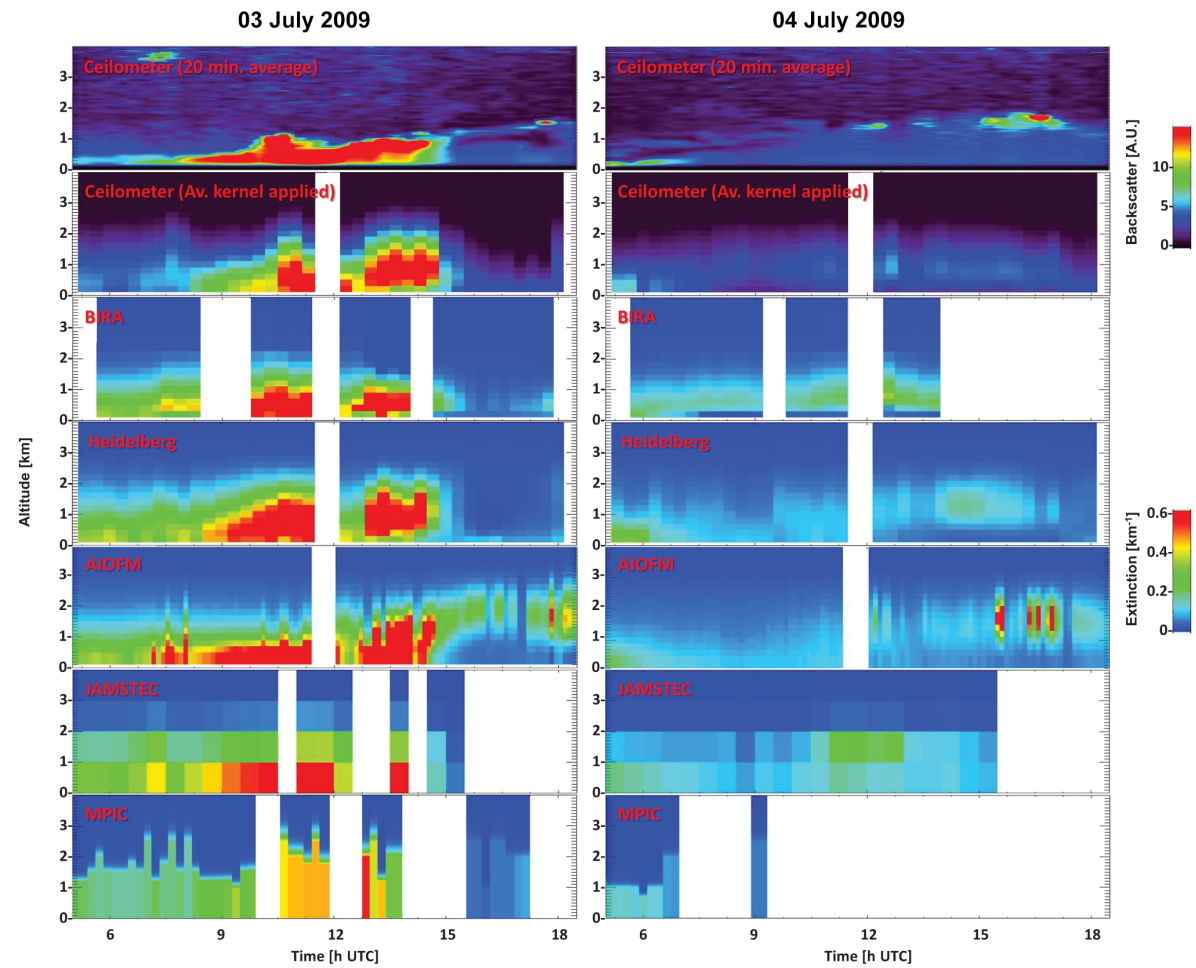

Figure 7. Same as Fig. 7 but for 3 July (left) 4 July (right). 

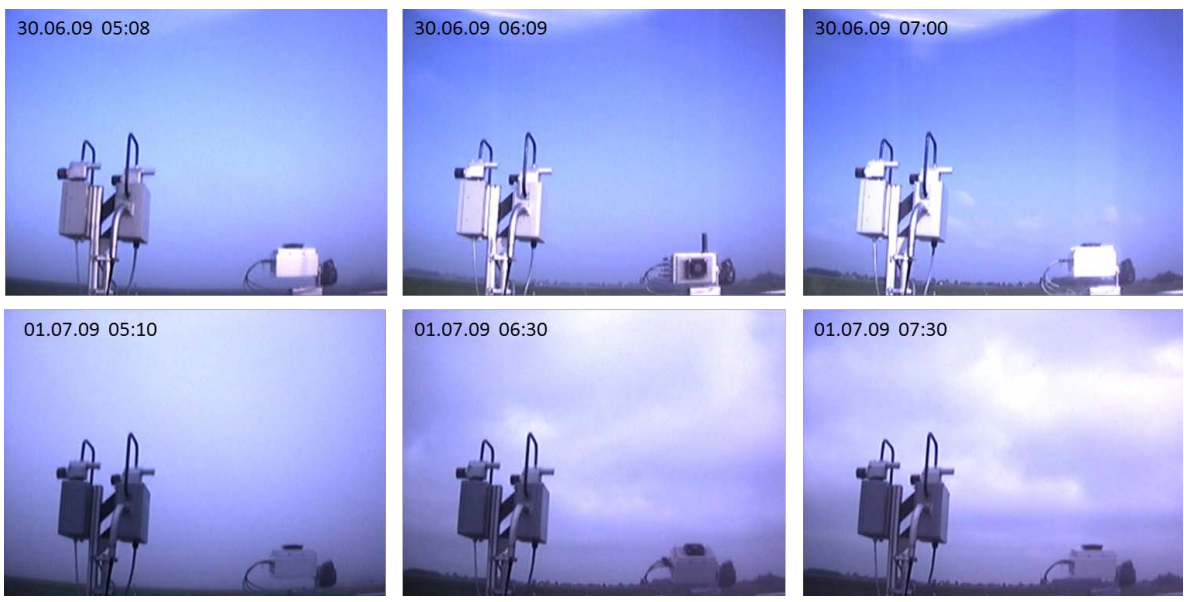

Figure 8. Webcam images from the mornings of 30 June and 1 July 2009, when foggy conditions prevailed. The webcam pointed to the viewing direction of the MAX-DOAS Instruments (north-east). The devices in the foreground are the telescopes of the Heidelberg group.

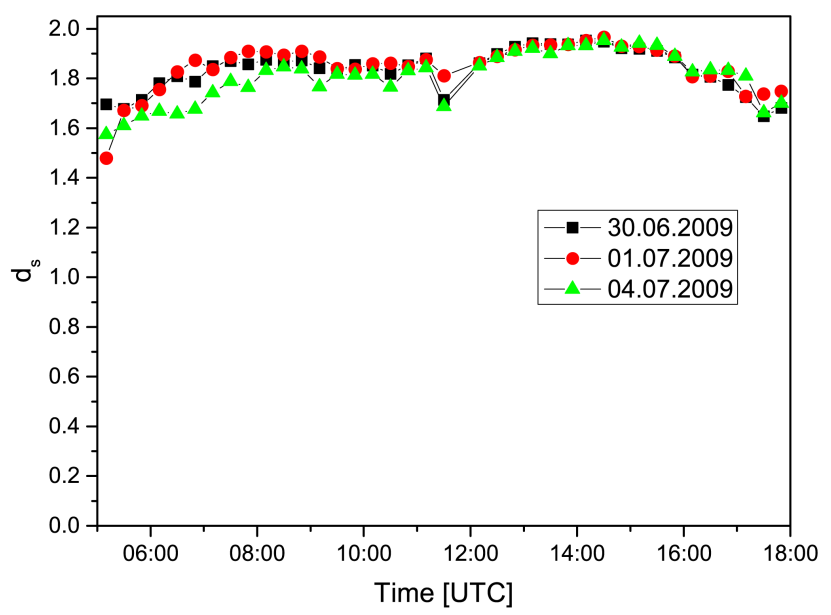

Figure 9. Diurnal variation of the degrees of freedom for signal from the Heidelberg retrieval for 30 June as well as 1 and 4 July 2009.

could lead to a reduced sensitivity for higher altitudes. This is in contrast to the situation on 25 June, when elevated layers could be detected during conditions of lower aerosol load.

Although the BIRA, Heidelberg, and AIOFM algorithms are very similar in terms of the parametrisation of the aerosol profile, the resulting profiles exhibit some differences, which can be caused either by a different choice of the a priori profiles and a priori covariance matrices or, in the case of BIRA, by a larger number of elevation angles with a higher sensitivity near the surface due to the inclusion of measurements at $1^{\circ}$ elevation. A persistent feature of the BIRA profiles is a reduced extinction in the lowermost (0-200 m) layer with significantly smaller values than in the layers above, even when the ceilometer indicates a homogeneous distribution in the boundary layer (e.g., on 24 and 25 June). However, the ceilometer does not have any information on altitudes below $150 \mathrm{~m}$, and it might well be that the surface acts as a sink for aerosols or that increased RH leads to larger particles and thus higher extinction at higher altitudes. In contrast, the BIRA and AIOFM algorithms seem to be able to capture uplifted layers or clouds better than the Heidelberg and JAMSTEC algorithms, e.g. in the afternoon of 30 June and the midday of 1 July. Both BIRA and JAMSTEC detect an uplifted layer of enhanced extinction the morning of 2 July, when clouds were present, a feature that is not captured by the Heidelberg and AIOFM algorithm. In some cases, such as the late afternoon of 2 and 3 July, the AIOFM profiles show an enhanced extinction between 1 and $2 \mathrm{~km}$ altitude, where the ceilometer also detects enhanced backscatter, probably due to clouds at the top of the boundary layer. This enhanced sensitivity for clouds at higher altitudes is probably due to the fact that the AIFOM algorithm includes relative intensities in addition to $\mathrm{O}_{4} \mathrm{dSCDs}$ in the measurement vector, which render the algorithm more sensitive to enhanced extinction at higher altitudes (Frieß et al., 2006). The AIOFM profiles exhibit a somewhat higher temporal variability, which is either due to the shorter time interval for each profile (about $7 \mathrm{~min}$ compared to 20 and $30 \mathrm{~min}$ for the other algorithms) or because the inclusion of relative intensities leads to a higher sensitivity to short-term variations due to clouds.

On 3 July a closed cloud cover is present between 08:30 and 14:30 UTC. The ceilometer profiles show that the cloud base is initially located at very low altitudes $(<250 \mathrm{~m})$ and increases in height in the early afternoon, leading to an uplifted layer after 12:00 UTC. These features are also present in the ceilometer profiles degraded with the MAX-DOAS averaging kernel. Under these conditions, the BIRA, Heidelberg, and AIOFM algorithms are able to retrieve the vertical structure of the boundary layer realistically, although some differences exist in the detailed structure and the height and vertical extent of the extinction layer in the afternoon. In particular, AIFOM does not detect the uplift until 13:30 UTC but 


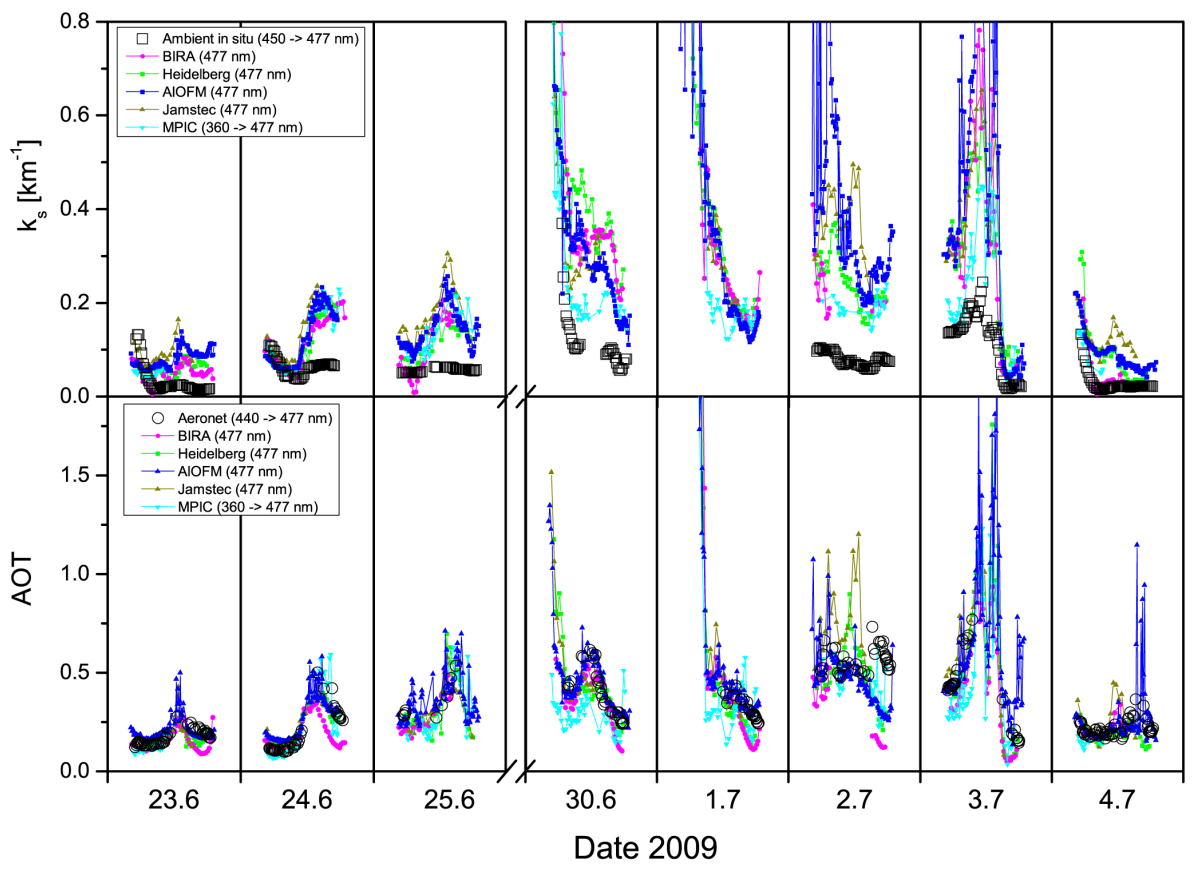

Figure 10. Time series of particle light extinction coefficient determined at the ground level (top) and AOT (bottom) from the MAX-DOAS retrieval (coloured symbols), together with the surface extinction from the humidity-controlled nephelometer (open squares) and the AOT from the sun photometer (open circles) for the golden days of the CINDI campaign. All data are converted to a wavelength of $477 \mathrm{~nm}$ using the Ångström coefficient derived from sun photometer measurements.

does detect enhanced extinction between 1 and $2 \mathrm{~km}$ altitude corresponding to a thin cloud layer at the top of the boundary layer visible in the ceilometer profiles between 14:00 and 18:00 UTC. In contrast, the coarse representation of the profile by JAMSTEC and the parametrised algorithm by MPIC both show an enhancement in extinction due to the presence of clouds but are not capable of retrieving the uplifted layer in the afternoon. The clouds apparent in the ceilometer profiles in the afternoon of 4 July between 15:30 and 18:00 UTC are identified in the extinction profiles retrieved by the AIOFM algorithm but not in the Heidelberg data (no other groups reported profiles for this period).

\subsection{Comparison of AOT and surface extinction}

In this section, the AOT and surface extinction derived by the different participants are compared to sun photometer and WetNeph measurements, respectively. The AOT is either derived by integrating the extinction profile (BIRA, Heidelberg, AIOFM, and JAMSTEC) or directly retrieved (MPIC). For BIRA, Heidelberg, AIOFM, and JAMSTEC, the value of the lowermost retrieval layer is considered as being representative for the surface extinction, whereas for MPIC the AOT divided by the layer height serves as an estimate. The time series of AOT and surface extinction for the golden days of the CINDI campaign are shown in Fig. 10.

An overall good agreement between the AOT from MAXDOAS and from the sun photometer is achieved. Under con- ditions of clear sky and low aerosol load (e.g., 23 and 24 June), BIRA tends to underestimate the AOT in the afternoon, when the relative azimuth angle (RAA) between viewing direction and Sun is small. In contrast, MPIC tends to underestimate the AOT in the morning under conditions of high aerosol load (1 and 3 July). Best agreement between all MAX-DOAS measurements as well as the sun photometer is achieved under clear sky conditions in the morning hours when the RAA is large (23 and 24 June as well as 4 July). The larger differences between the different groups at higher and more variable aerosol load (30 June-3 July) are caused either by differences in the retrieval algorithm or by slightly different temporal and/or spatial sampling (i.e., slightly different viewing directions). As already discussed in Sect. 3.1, the very high AOT and surface extinction values observed during the morning of 30 June and 1 July are caused by fog. Unfortunately, no sun photometer measurements are available for these periods since these rely on the observation of direct sunlight. The same applies to the morning of 25 June and the noon of 3 July. However, the overall good agreement between the vertical profiles from MAX-DOAS and ceilometer (see Sect. 3.1) provide confidence that the AOT can be retrieved reliably even under these conditions of reduced visibility.

A sudden jump in the AOT values from the sun photometer occurs on 2 July at 14:30 UTC but is not apparent in the MAX-DOAS data. It is not clear whether this is caused by lo- 
Table 2. Comparison between the AOT from MAX-DOAS and from sun photometer. Listed are the number of data points, intercept, and slope of the linear regression, the correlation coefficient $R$, the mean difference (MAX-DOAS minus sun photometer), and the standard deviation of the mean difference.

\begin{tabular}{lrlllllrr}
\hline Participant & $N$ & \multicolumn{2}{c}{ Intercept } & \multicolumn{2}{c}{ Slope } & \multicolumn{2}{c}{$\Delta$} & \multicolumn{2}{c}{$\Delta$ AOT } \\
\hline AIOFM & 431 & 0.071 & 0.007 & 0.795 & 0.023 & 0.86 & 0.011 & 0.079 \\
BIRA & 140 & 0.021 & 0.014 & 0.702 & 0.045 & 0.80 & -0.062 & 0.083 \\
Heidelberg & 149 & 0.027 & 0.012 & 0.805 & 0.037 & 0.87 & -0.031 & 0.078 \\
JAMSTEC & 73 & 0.040 & 0.022 & 0.902 & 0.062 & 0.86 & 0.010 & 0.092 \\
MPIC & 128 & 0.039 & 0.014 & 0.622 & 0.040 & 0.81 & -0.071 & 0.100 \\
\hline
\end{tabular}

* Only data points before 16:00 UTC are reported
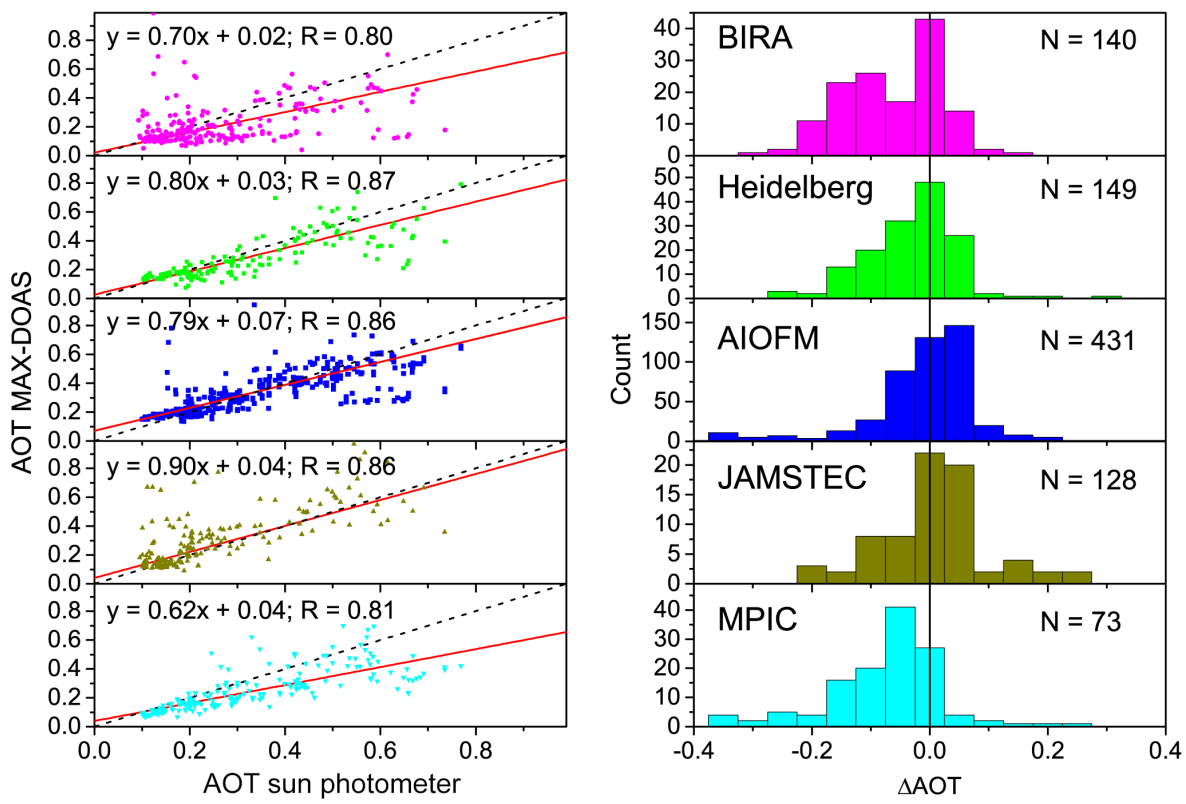

Figure 11. Left panels: correlation between AOT from the different groups and from the sun photometer. The red line shows the linear fit and the dashed line the $1: 1$ line. Right panels: histograms of the difference in AOT (MAX-DOAS - sun photometer).

cal aerosols not captured by the MAX-DOAS instrument due to the different viewing geometry or by erroneous sun photometer data. For these reasons, the data of the afternoon of 2 July are excluded from the following correlation analysis.

The correlation between the AOT from MAX-DOAS and from sun photometer as well as histograms for the AOT difference (MAX-DOAS minus sun photometer) for the different groups are shown in Fig. 11. The results of the regression analyses are listed in Table 2 . The correlation coefficient is $>0.8$ for all groups, and the mean difference between AOT from MAX-DOAS and sun photometer is -0.07 with a standard deviation $<0.1$. All datasets exhibit a slope significantly smaller than 1 , ranging from 0.62 (MPIC) to 0.90 (JAMSTEC). This systematic underestimation of the AOT is likely to be caused by both the fact that the sensitivity for high altitudes is low and that the partial AOT above the altitude where aerosol extinction have been retrieved $(4 \mathrm{~km})$ has not been considered in this analysis. Best agreement in terms of slope (0.9) and mean difference to sun photometer measurements (0.01) is achieved by JAMSTEC. However, compared to the other participants the difference of JAMSTEC data to sun photometer AOT shows a large scatter (0.092), and no data have been submitted by JAMSTEC for the late afternoon (after 16:00 UTC) when the RAA is small and systematic problems with the retrieval might occur, leading to the smallest number of data points (73) submitted by this group.

It is important to note that parts of the discrepancies between the AOT from different groups originate not only from the different retrieval strategies and parametrisations, as well as from the different time periods for which data are available from the different groups, but also, in the case of MPIC, from the fact that the inversions are based on $\mathrm{O}_{4}$ measurements at a different wavelength. The MPIC retrieval is based on measurements of the $360 \mathrm{~nm} \mathrm{O} 4$ absorption band, and the retrieved extinction is converted to $477 \mathrm{~nm}$ using the Ångström 
Table 3. Comparison between the surface extinction from MAX-DOAS and from WetNeph. Listed are the number of data points, intercept, and slope of the linear regression, the correlation coefficient $R$, the mean difference (MAX-DOAS minus WetNeph), and the standard deviation of the mean difference. All extinction values are in units of $\mathrm{km}^{-1}$.

\begin{tabular}{lrrrrrrrr}
\hline Participant & $N$ & \multicolumn{2}{c}{ Intercept } & \multicolumn{2}{c}{ Slope } & \multicolumn{2}{c}{$R$} & \multicolumn{2}{c}{$\Delta$ AOT } \\
\hline AIOFM & 617 & -0.025 & 0.017 & 3.773 & 0.200 & 0.61 & 0.165 & 0.298 \\
BIRA & 180 & 0.014 & 0.006 & 1.638 & 0.115 & 0.73 & 0.096 & 0.122 \\
Heidelberg $^{*}$ & 215 & 0.023 & 0.007 & 2.328 & 0.086 & 0.88 & 0.105 & 0.099 \\
JAMSTEC $^{*}$ & 112 & 0.046 & 0.008 & 1.214 & 0.144 & 0.63 & 0.132 & 0.103 \\
MPIC & 158 & 0.025 & 0.011 & 1.492 & 0.099 & 0.77 & 0.070 & 0.076 \\
\hline
\end{tabular}

* Only data points before 16:00 UTC are reported
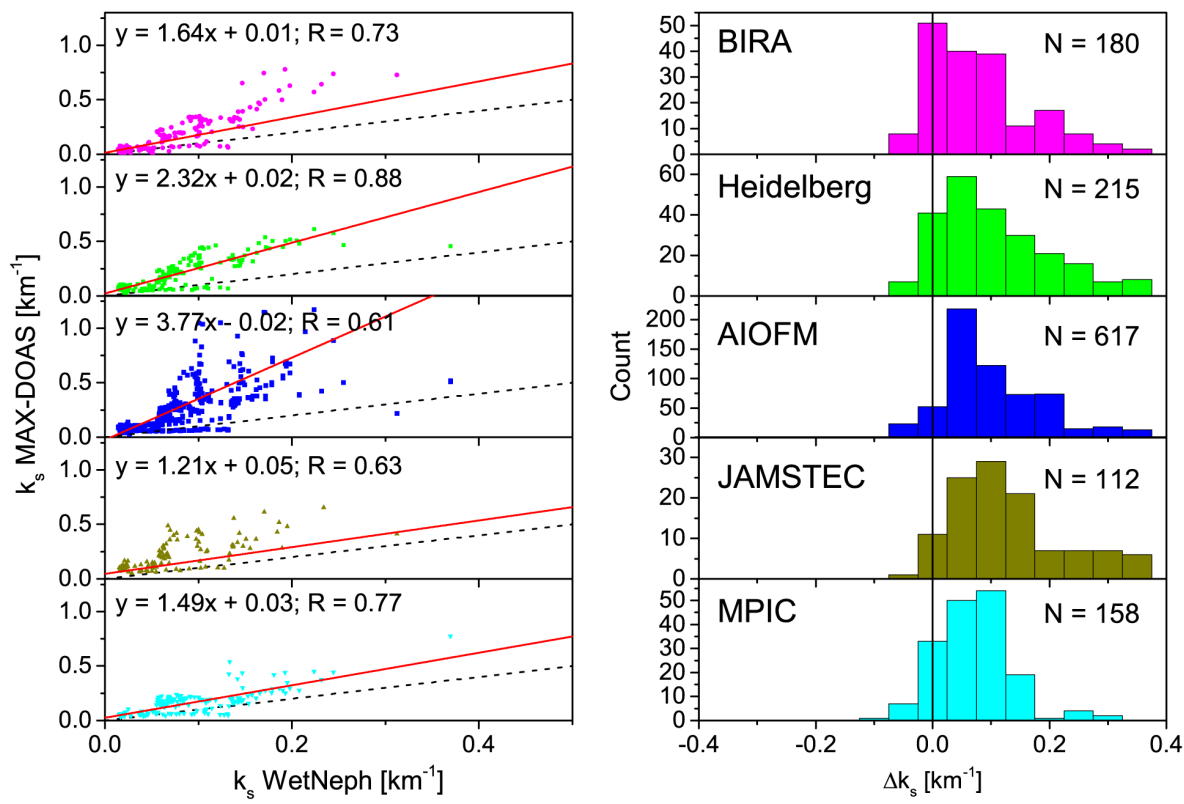

Figure 12. Left panels: correlation between surface extinction from the different groups and from WetNeph. The red line shows the linear fit and the dashed line the $1: 1$ line. Right panels: histograms of the difference in surface extinction (MAX-DOAS - WetNeph).

coefficient derived from co-located sun photometer measurements. Therefore likely reasons for the small slope in the AOT comparison between MPIC and sun photometer are both the uncertainties in the Angström coefficient and the reduced visibility in the UV, which leads to a different horizontal footprint of the MPIC observations.

As shown in the upper panel of Fig. 10, a strong disagreement exists between the surface extinction of the different MAX-DOAS retrievals and the in situ measurements from the WetNeph instrument, especially in the afternoon and during periods of high aerosol load. The WetNeph observes a much smaller extinction than all MAX-DOAS retrievals for most of the time. This is also apparent in the correlation plots and the histograms of differences between MAX-DOAS and WetNeph surface extinction shown in Fig. 12. A summary of the regression analysis for surface extinction is shown in Table 3. Note that the regression analysis yields values different to those reported by Zieger et al. (2011). This is first because different samples are compared (in the present study only data from the golden days are considered) and second because Zieger et al. (2011) applied a weighted orthogonal fit, whereas here a usual linear regression has been used. Best agreement in terms of mean difference between MAXDOAS and WetNeph is achieved by the parametrised MPIC algorithm, which is not capable of directly determining gradients in the aerosol extinction near the surface. Hence a possible explanation for the strong discrepancies observed for the OEM algorithms (BIRA, Heidelberg, AIOFM, and JAMSTEC) could be a strong increase in extinction below the height of the WetNeph inlet ( $60 \mathrm{~m}$ above ground). Further possible reasons for these discrepancies and a comprehensive statistical analysis of data from the CESAR site for an extended period of time have already been discussed in detail by Zieger et al. (2011). We still do not have a conclusive explanation for the origin of these differences, in particular 
since both the AOT and the vertical structure of the boundary layer are captured well by the MAX-DOAS vertical profiles.

Surface extinction values from the different MAX-DOAS algorithms show good agreement during conditions of low aerosol (23-26 June) but exhibit significant discrepancies at higher aerosol load (e.g., 30 June-3 July). Again, a likely reason for parts of the discrepancies in surface extinction between the different MAX-DOAS retrievals is the fact that different parametrisations of the extinction profile are used. Since RH tends to increase with altitude in the boundary layer, hygroscopic growth of aerosol particles usually leads to an increase in extinction with altitude. Moreover, gas may partition to aerosol as RH increases and temperature reduces with increasing altitude, and ammonium and nitrate were observed to increase with altitude in the vicinity of Cabauw (Morgan et al., 2010; Aan de Brugh et al., 2012). An inhomogeneous vertical distribution leads to erroneous estimates of the surface extinction for models with a coarse vertical grid (JAMSTEC) or with parametrised retrievals (MPIC). JAMSTEC represents the extinction profile on a $1 \mathrm{~km}$ vertical grid and should for these reasons tend to overestimate the surface extinction if extinction increases with altitude. The same should be true for MPIC, for which the surface extinction (or rather the average boundary layer extinction) is estimated by dividing the AOT by the retrieved layer height. Indeed, JAMSTEC retrieves the highest AOTs, whereas MPIC retrieves a smaller extinction than the other groups under conditions of high aerosol load and large vertical gradients (30 June to 3 July). Although Heidelberg, BIRA, and AIOFM use the same vertical grid with a layer thickness of $200 \mathrm{~m}$ and comparable retrieval algorithms, surface extinction values from these groups show significant discrepancies in cases of high aerosol load or fog, e.g. in the morning of 30 June, on 2 July, and in the afternoon of 4 July.

In summary, possible reasons for the observed discrepancies between surface extinction from MAX-DOAS and WetNeph are (1) strong vertical gradients of the aerosol extinction with increased extinction below the height of the WetNeph inlet, (2) problems of the MAX-DOAS retrieval algorithms in the presence of nonhomogeneous horizontal distributions (although these are not very likely given the smooth temporal variations of the MAX-DOAS and in situ data), (3) the overestimation of the surface extinction by MAX-DOAS in the presence of lofted layers, as well as (4) inlet losses of the in situ instruments. Note that the extinction profiles estimated from a co-located Raman LIDAR instrument agreed much better to the in situ WetNeph values, although only a limited number of profiles could be compared, and a Mie closure showed the consistency of all major aerosol in situ measurements in the basement of the CESAR tower (Zieger et al., 2011).

\section{Conclusions}

We have presented a first direct intercomparison of aerosol extinction profiles, AOT, and surface extinction from MAXDOAS measurements. MAX-DOAS data collected during the CINDI campaign have been compared to independent measurements of the AOT from an AERONET sun photometer, of the vertical structure from a commercial ceilometer instrument, and of the surface extinction from in situ instruments.

The retrieval algorithms that were part of this study follow very different approaches and use different parametrisations of the aerosol vertical profiles. BIRA, Heidelberg, AIOFM, and JAMSTEC use the optimal estimation method and retrieve the extinction profiles at different altitude grids (BIRA, AIOFM, and Heidelberg: $200 \mathrm{~m}$ layers; JAMSTEC: $1 \mathrm{~km}$ layers). MPIC uses a least-squares algorithm with the AOT and layer height as retrieval parameters and no further a priori constraints.

Despite large conceptual differences between the algorithms and different representations of the aerosol extinction profile, and although the information content of the MAXDOAS measurements is low (typically in the order of 2 DFS), the comparison of the retrieved profiles with ceilometer backscatter profiles shows that all algorithms are able to provide an estimate for the vertical extent of the boundary layer with the expected accuracy. BIRA, AIOFM, and Heidelberg with the finest vertical grid of $200 \mathrm{~m}$, but also to a certain extent JAMSTEC with a $1 \mathrm{~km}$ vertical grid, are able to resolve the vertical structure of the boundary layer and to detect uplifted aerosol layers, fog, and clouds in the lowermost $\approx 1.5 \mathrm{~km}$ of the atmosphere. The vertical resolution is, however, limited by the small information content of the measurements and is $\approx 500 \mathrm{~m}$ at the surface and $\approx 1 \mathrm{~km}$ at $1 \mathrm{~km}$ altitude. Therefore, thin layers of high extinction, such as fog, appear strongly blurred in the retrieved extinction profiles. Unfortunately, the AOT retrieved under conditions of low visibility is difficult to validate since sun photometer measurements, which rely on direct sunlight, are not available for these periods.

In general, the time series of AOT retrieved from MAXDOAS shows good agreement with co-located sun photometer measurements. A regression analysis shows correlation coefficients better than 0.8 for all groups. All retrieval algorithms systematically underestimate the AOT with slopes of ranging from 0.6 to 0.9 and mean AOT differences (MAXDOAS minus sun photometer) of less than 0.07. It is important to note that parts of the differences between MAXDOAS and sun photometer are probably due to the fact that both kinds of instruments observe different air masses in a highly populated and polluted region where horizontal gradients in aerosol load are likely to occur. Furthermore, MAXDOAS is insensitive to aerosols above $\approx 2 \mathrm{~km}$. In the case of MPIC, additional systematic differences might be caused by the conversion of the AOT from 360 to $477 \mathrm{~nm}$. A further 
source of the observed discrepancies is the empirical correction factor for the $\mathrm{O}_{4} \mathrm{dSCDs}$, for which different approaches were applied. AIOFM, MPIC, and BIRA use a constant value of 0.77 to 0.8 , JAMSTEC implements a variable correction factor, whereas no correction factor was applied by the Heidelberg group. This correction factor has not been the focus of the present paper, but recent studies indicate that the disagreement between modelled and measured $\mathrm{O}_{4}$ dSCDs is probably not caused by uncertainties in the temperature dependence of the $\mathrm{O}_{4}$ cross section but rather by elevated aerosol layers (Spinei et al., 2015; Ortega et al., 2016).

Given that the AOT and the vertical structure of the extinction profiles are captured reasonably well by the different retrieval algorithms, it remains open as to why there is such a large discrepancy between the surface extinction from MAX-DOAS and from WetNeph. In particular in the afternoon, the WetNeph shows much smaller values than retrieved by MAX-DOAS. Significant differences between the individual MAX-DOAS retrievals, in particular under conditions of high aerosol load and large vertical gradients, can be partially explained by the different parametrisations of the vertical profile. Furthermore, strong vertical gradients in aerosol extinction near the surface are a potential reason for the observed discrepancies.

Although the ability of MAX-DOAS measurements to determine vertical profiles of aerosols is limited by a small information content and a relatively low vertical resolution, this intercomparison study shows that the MAX-DOAS technique can reliably determine the vertical structure of the lowermost $2 \mathrm{~km}$ of the atmosphere, and observations are not limited to clear sky conditions but can also be performed during situations of low visibility.

With respect to future intercomparisons of MAX-DOAS aerosol products, e.g. during the upcoming CINDI-II campaign in September 2016, one might consider extending measurements and retrieval algorithms in several ways. First, it has been demonstrated recently that the 3-D distribution of trace gases can be retrieved from azimuthal scans (Ortega et al., 2015). Many MAX-DOAS instruments are nowadays capable of scanning not only at different elevation angles but also in azimuthal direction, and a similar approach as suggested by Ortega et al. (2015) for trace gases can be used in future campaigns in order to quantify horizontal inhomogeneities of the aerosol distribution. Second, azimuthal scans contain information on aerosol optical and microphysical properties (Frieß et al., 2006), but algorithms capable of retrieving this information have not been compared and validated against independent instrumentation yet. Third, an important factor affecting the quality of the aerosol and trace gas profile retrieval from MAX-DOAS measurements is the presence of clouds. In the present study, the intercomparison has been restricted to mostly cloud-free conditions, but the observations during foggy conditions have shown that a meaningful retrieval of profile information is possible even for situations with low visibility. An inclusion of measure- ments during cloudy conditions would allow for testing the capabilities and limitations of the retrieval algorithm under more adverse conditions. Furthermore, a reliable cloud flagging is of great importance for the quality assessment of MAX-DOAS data products. Different approaches for the detection of clouds from MAX-DOAS measurements have been suggested recently (Gielen et al., 2014; Wagner et al., 2014), and future campaigns would offer the opportunity to test these cloud-flagging algorithms and to investigate their applicability to MAX-DOAS aerosol and trace gas retrieval products. Finally, further sensitivity studies on the basis of simultaneous MAX-DOAS and LIDAR measurements during future campaigns should focus on the observed disagreement between modelled and measured $\mathrm{O}_{4} \mathrm{dSCDs}$, including the potential impact of uplifted layers of aerosols on MAX$\mathrm{DOAS} \mathrm{O}_{4}$ measurements.

\section{Data availability}

The data used for this study are available from the authors upon request.

Acknowledgements. The CINDI Campaign was for a large part funded by the ESA project CEOS Intercalibration of ground-based spectrometers and lidars (ESRIN contract 22202/09/I-EC) and the EU project ACCENT-AT2 (GOCE-CT-2004-505337). We further acknowledge the support of the EU via the GEOMon Integrated Project (contract FP6-2005-Global-4-036677). The work of Frieß and Yilmaz has been financially supported by the EU Project EUSAAR (contract 2006-026140). Many thanks to Ankie Piters, Jennifer Hains, and Mark Kroon for hosting the campaign and for the superb organisation. The excellent logistical support by Jacques Warmer and the staff of KNMI at the CESAR site is gratefully acknowledged. Many thanks to Alexei Rozanov from IUP Bremen for providing the SCIATRAN radiative transfer model.

Edited by: W. R. Simpson

Reviewed by: two anonymous referees

\section{References}

Aan de Brugh, J. M. J., Henzing, J. S., Schaap, M., Morgan, W. T., van Heerwaarden, C. C., Weijers, E. P., Coe, H., and Krol, M. C.: Modelling the partitioning of ammonium nitrate in the convective boundary layer, Atmos. Chem. Phys., 12, 3005-3023, doi:10.5194/acp-12-3005-2012, 2012.

Ammann, M., Kalberer, M., Jost, D. T., Tobler, L., Rossler, E., Piguet, D., Gaggeler, H. W., and Baltensperger, U.: Heterogeneous production of nitrous acid on soot in polluted air masses, Nature, 395, 157-160, doi:10.1038/25965, 1998.

Clémer, K., Van Roozendael, M., Fayt, C., Hendrick, F., Hermans, C., Pinardi, G., Spurr, R., Wang, P., and De Mazière, M.: Multiple wavelength retrieval of tropospheric aerosol optical properties from MAXDOAS measurements in Beijing, Atmos. Meas. Tech., 3, 863-878, doi:10.5194/amt-3-863-2010, 2010. 
Crutzen, P. J. and Arnold, F.: Nitric acid cloud formation in the cold Antarctic stratosphere: a major cause for the springtime 'ozone hole', Nature, 324, 651-655, doi:10.1038/324651a0, 1986.

Deutschmann, T., Beirle, S., Frieß, U., Grzegorski, M., Kern, C., Kritten, L., Platt, U., Prados-Roman, C., Puķīte, J., Wagner, T., Werner, B., and Pfeilsticker, K.: The Monte Carlo atmospheric radiative transfer model McArtim: Introduction and validation of Jacobians and 3D features, J. Quant. Spec. Rad. Trans., 112, 1119-1137, doi:10.1016/j.jqsrt.2010.12.009, 2011.

Dubovik, O., Holben, B., Eck, T., Smirnov, A., Kaufman, Y., King, M., Tanré, D., and Slutsker, I.: Variability of absorption and optical properties of key aerosol types observed in worldwide locations, J. Atmos. Sci., 59, 590-608, doi:10.1175/15200469(2002)059<0590:VOAAOP>2.0.CO;2, 2002.

Fierz-Schmidhauser, R., Zieger, P., Wehrle, G., Jefferson, A., Ogren, J. A., Baltensperger, U., and Weingartner, E.: Measurement of relative humidity dependent light scattering of aerosols, Atmos. Meas. Tech., 3, 39-50, doi:10.5194/amt-3-392010, 2010.

Frieß, U., Monks, P., Remedios, J., Rozanov, A., Sinreich, R., Wagner, T., and Platt, U.: MAX-DOAS $\mathrm{O}_{4}$ measurements: A new technique to derive information on atmospheric aerosols: 2. Modeling studies, J. Geophys. Res., 111, D14203, doi:10.1029/2005JD006618, 2006.

Frieß, U., Sihler, H., Sander, R., Pöhler, D., Yilmaz, S., and Platt, U.: The vertical distribution of $\mathrm{BrO}$ and aerosols in the Arctic: Measurements by active and passive differential optical absorption spectroscopy, J. Geophys. Res., 116, D00R04, doi:10.1029/2011JD015938, 2011.

Gielen, C., Van Roozendael, M., Hendrick, F., Pinardi, G., Vlemmix, T., De Bock, V., De Backer, H., Fayt, C., Hermans, C., Gillotay, D., and Wang, P.: A simple and versatile cloudscreening method for MAX-DOAS retrievals, Atmos. Meas. Tech., 7, 3509-3527, doi:10.5194/amt-7-3509-2014, 2014.

Greenblatt, G. D., Orlando, J. J., Burkholder, J. B., and Ravishankara, A. R.: Absorption Measurements of Oxygen Between 330 and $1140 \mathrm{~nm}$, J. Geophys. Res., 95, 18577-18582, doi:10.1029/JD095iD11p18577, 1990.

Hendrick, F., Müller, J.-F., Clémer, K., Wang, P., De Mazière, M., Fayt, C., Gielen, C., Hermans, C., Ma, J. Z., Pinardi, G., Stavrakou, T., Vlemmix, T., and Van Roozendael, M.: Four years of ground-based MAX-DOAS observations of HONO and $\mathrm{NO}_{2}$ in the Beijing area, Atmos. Chem. Phys., 14, 765-781, doi:10.5194/acp-14-765-2014, 2014.

Hönninger, G., von Friedeburg, C., and Platt, U.: Multi axis differential optical absorption spectroscopy (MAX-DOAS), Atmos. Chem. Phys., 4, 231-254, doi:10.5194/acp-4-231-2004, 2004.

Irie, H., Kanaya, Y., Akimoto, H., Iwabuchi, H., Shimizu, A., and Aoki, K.: First retrieval of tropospheric aerosol profiles using MAX-DOAS and comparison with lidar and sky radiometer measurements, Atmos. Chem. Phys., 8, 341-350, doi:10.5194/acp-8341-2008, 2008.

Irie, H., Kanaya, Y., Akimoto, H., Iwabuchi, H., Shimizu, A., and Aoki, K.: Dual-wavelength aerosol vertical profile measurements by MAX-DOAS at Tsukuba, Japan, Atmos. Chem. Phys., 9, 2741-2749, doi:10.5194/acp-9-2741-2009, 2009.

Irie, H., Takashima, H., Kanaya, Y., Boersma, K. F., Gast, L., Wittrock, F., Brunner, D., Zhou, Y., and Van Roozendael, M.: Eightcomponent retrievals from ground-based MAX-DOAS observa- tions, Atmos. Meas. Tech., 4, 1027-1044, doi:10.5194/amt-41027-2011, 2011.

Iwabuchi, H.: Efficient Monitoringnte Carlo Methods for Radiative Transfer Modeling, J. Atmos. Sci., 63, 2324-2339, doi:10.1175/JAS3755.1, 2006.

Lee, H., Irie, H., Kim, Y. J., Noh, Y., Lee, C., Kim, Y., and Chun, K. J.: Retrieval of Aerosol Extinction in the Lower Troposphere Based on UV MAX-DOAS Measurements, Aerosol Sci. Technol., 43, 502-509, doi:10.1080/02786820902769691, 2009.

Li, X., Brauers, T., Shao, M., Garland, R. M., Wagner, T., Deutschmann, T., and Wahner, A.: MAX-DOAS measurements in southern China: retrieval of aerosol extinctions and validation using ground-based in-situ data, Atmos. Chem. Phys., 10, 2079 2089, doi:10.5194/acp-10-2079-2010, 2010.

Morgan, W. T., Allan, J. D., Bower, K. N., Esselborn, M., Harris, B., Henzing, J. S., Highwood, E. J., Kiendler-Scharr, A., McMeeking, G. R., Mensah, A. A., Northway, M. J., Osborne, S., Williams, P. I., Krejci, R., and Coe, H.: Enhancement of the aerosol direct radiative effect by semi-volatile aerosol components: airborne measurements in North-Western Europe, Atmos. Chem. Phys., 10, 8151-8171, doi:10.5194/acp-10-81512010, 2010.

Ortega, I., Koenig, T., Sinreich, R., Thomson, D., and Volkamer, R.: The CU 2-D-MAX-DOAS instrument - Part 1: Retrieval of 3-D distributions of $\mathrm{NO}_{2}$ and azimuth-dependent OVOC ratios, Atmos. Meas. Tech., 8, 2371-2395, doi:10.5194/amt-8-2371-2015, 2015.

Ortega, I., Berg, L. K., Ferrare, R. A., Hair, J. W., Hostetler, C. A., and Volkamer, R.: Elevated aerosol layers modify the $\mathrm{O}_{2}$ absorption measured by ground-based MAX-DOAS, J. Quant. Spectrosc. Ra. Transfer, 176, 34-49, doi:10.1016/j.jqsrt.2016.02.021, 2016.

Piters, A. J. M., Boersma, K. F., Kroon, M., Hains, J. C., Van Roozendael, M., Wittrock, F., Abuhassan, N., Adams, C., Akrami, M., Allaart, M. A. F., Apituley, A., Beirle, S., Bergwerff, J. B., Berkhout, A. J. C., Brunner, D., Cede, A., Chong, J., Clémer, K., Fayt, C., Frieß, U., Gast, L. F. L., Gil-Ojeda, M., Goutail, F., Graves, R., Griesfeller, A., Großmann, K., Hemerijckx, G., Hendrick, F., Henzing, B., Herman, J., Hermans, C., Hoexum, M., van der Hoff, G. R., Irie, H., Johnston, P. V., Kanaya, Y., Kim, Y. J., Klein Baltink, H., Kreher, K., de Leeuw, G., Leigh, R., Merlaud, A., Moerman, M. M., Monks, P. S., Mount, G. H., Navarro-Comas, M., Oetjen, H., Pazmino, A., Perez-Camacho, M., Peters, E., du Piesanie, A., Pinardi, G., Puentedura, O., Richter, A., Roscoe, H. K., Schönhardt, A., Schwarzenbach, B., Shaiganfar, R., Sluis, W., Spinei, E., Stolk, A. P., Strong, K., Swart, D. P. J., Takashima, H., Vlemmix, T., Vrekoussis, M., Wagner, T., Whyte, C., Wilson, K. M., Yela, M., Yilmaz, S., Zieger, P., and Zhou, Y.: The Cabauw Intercomparison campaign for Nitrogen Dioxide measuring Instruments (CINDI): design, execution, and early results, Atmos. Meas. Tech., 5, 457-485, doi:10.5194/amt-5-457-2012, 2012.

Rodgers, C. and Connor, B.: Intercomparison of remote sounding instruments, J. Geophys. Res., 108, 4116-4229, doi:10.1029/2002JD002299, 2003.

Rodgers, C. D.: Inverse methods for atmospheric sounding, theory and practice, Series on Atmospheric, Oceanic and Planetary Physics, World Scientific, 2000. 
Roscoe, H. K., Van Roozendael, M., Fayt, C., du Piesanie, A., Abuhassan, N., Adams, C., Akrami, M., Cede, A., Chong, J., Clémer, K., Friess, U., Gil Ojeda, M., Goutail, F., Graves, R., Griesfeller, A., Grossmann, K., Hemerijckx, G., Hendrick, F., Herman, J., Hermans, C., Irie, H., Johnston, P. V., Kanaya, Y., Kreher, K., Leigh, R., Merlaud, A., Mount, G. H., Navarro, M., Oetjen, H., Pazmino, A., Perez-Camacho, M., Peters, E., Pinardi, G., Puentedura, O., Richter, A., Schönhardt, A., Shaiganfar, R., Spinei, E., Strong, K., Takashima, H., Vlemmix, T., Vrekoussis, M., Wagner, T., Wittrock, F., Yela, M., Yilmaz, S., Boersma, F., Hains, J., Kroon, M., Piters, A., and Kim, Y. J.: Intercomparison of slant column measurements of $\mathrm{NO}_{2}$ and $\mathrm{O}_{4}$ by MAX-DOAS and zenith-sky UV and visible spectrometers, Atmos. Meas. Tech., 3, 1629-1646, doi:10.5194/amt-3-1629-2010, 2010.

Rozanov, A., Bovensmann, H., Bracher, A., Hrechanyy, S., Rozanov, V., Sinnhuber, M., Stroh, F., and Burrows, J.: $\mathrm{NO}_{2}$ and $\mathrm{BrO}$ vertical profile retrieval from SCIAMACHY limb measurements: Sensitivity studies, Adv. Space Res., 36, 846-854, doi:10.1016/j.asr.2005.03.013, 2005a.

Rozanov, A., Rozanov, V., Buchwitz, M., Kokhanovsky, A., and Burrows, J.: Atmospheric Remote Sensing: Earth's Surface, Troposphere, Stratosphere and Mesosphere, vol. 16, chap. SCIATRAN 2.0 - A new radiative transfer model for geophysical applications in the 175-2400 nm spectral region, 1015-1019, Advances in Space Res, 2005b.

Simpson, W. R., von Glasow, R., Riedel, K., Anderson, P., Ariya, P., Bottenheim, J., Burrows, J., Carpenter, L. J., Frieß, U., Goodsite, M. E., Heard, D., Hutterli, M., Jacobi, H.-W., Kaleschke, L., Neff, B., Plane, J., Platt, U., Richter, A., Roscoe, H., Sander, R., Shepson, P., Sodeau, J., Steffen, A., Wagner, T., and Wolff, E.: Halogens and their role in polar boundary-layer ozone depletion, Atmos. Chem. Phys., 7, 4375-4418, doi:10.5194/acp-74375-2007, 2007.

Sinreich, R., Merten, A., Molina, L., and Volkamer, R.: Parameterizing radiative transfer to convert MAX-DOAS dSCDs into near-surface box-averaged mixing ratios, Atmos. Meas. Tech., 6, 1521-1532, doi:10.5194/amt-6-1521-2013, 2013.

Spinei, E., Cede, A., Herman, J., Mount, G. H., Eloranta, E., Morley, B., Baidar, S., Dix, B., Ortega, I., Koenig, T., and Volkamer, R.: Ground-based direct-sun DOAS and airborne MAX-DOAS measurements of the collision-induced oxygen complex, $\mathrm{O}_{2} \mathrm{O}_{2}$, absorption with significant pressure and temperature differences, Atmos. Meas. Tech., 8, 793-809, doi:10.5194/amt-8-793-2015, 2015.

Spurr, R.: LIDORT and VLIDORT: Linearized pseudo-spherical scalar and vector discrete ordinate radiative transfer models for use in remote sensing retrieval problems, in: Light Scattering Reviews 3, edited by: Kokhanovsky, A., Springer Praxis Books, 229-275, Springer Berlin Heidelberg, doi:10.1007/978-3-54048546-9_7, 2008.

Stocker, T., Qin, D., Plattner, G.-K., Tignor, M., Allen, S., Boschung, J., Nauels, A., Xia, Y., Bex, V., and Midgley, P. (Eds.): Climate Change 2013: The Physical Science Basis, Cambridge University Press, Cambridge, United Kingdom and New York, NY, USA, 2013.

Takashima, H., Irie, H., Kanaya, Y., Shimizu, A., Aoki, K., and Akimoto, H.: Atmospheric aerosol variations at Okinawa Island in Japan observed by MAX-DOAS using a new cloud-screening method, J. Geophys. Res., 114, D18213, doi:10.1029/2009JD011939, 2009.

Vlemmix, T., Piters, A. J. M., Stammes, P., Wang, P., and Levelt, P. F.: Retrieval of tropospheric $\mathrm{NO}_{2}$ using the MAX-DOAS method combined with relative intensity measurements for aerosol correction, Atmos. Meas. Tech., 3, 1287-1305, doi:10.5194/amt-31287-2010, 2010.

Vlemmix, T., Hendrick, F., Pinardi, G., De Smedt, I., Fayt, C., Hermans, C., Piters, A., Wang, P., Levelt, P., and Van Roozendael, M.: MAX-DOAS observations of aerosols, formaldehyde and nitrogen dioxide in the Beijing area: comparison of two profile retrieval approaches, Atmos. Meas. Tech., 8, 941-963, doi:10.5194/amt-8-941-2015, 2015.

Wagner, T., Dix, B., von Friedeburg, C., Frieß, U., Sanghavi, S., Sinreich, R., and Platt, U.: MAX-DOAS O 4 measurements: A new technique to derive information on atmospheric aerosols - principles and information content, J. Geophys. Res., 109, D22205, doi:10.1029/2004JD004904, 2004.

Wagner, T., Beirle, S., Brauers, T., Deutschmann, T., Frieß, U., Hak, C., Halla, J. D., Heue, K. P., Junkermann, W., Li, X., Platt, U., and Pundt-Gruber, I.: Inversion of tropospheric profiles of aerosol extinction and $\mathrm{HCHO}$ and $\mathrm{NO}_{2}$ mixing ratios from MAX-DOAS observations in Milano during the summer of 2003 and comparison with independent data sets, Atmos. Meas. Tech., 4, 2685-2715, doi:10.5194/amt-4-2685-2011, 2011.

Wagner, T., Apituley, A., Beirle, S., Dörner, S., Friess, U., Remmers, J., and Shaiganfar, R.: Cloud detection and classification based on MAX-DOAS observations, Atmos. Meas. Tech., 7, 1289-1320, doi:10.5194/amt-7-1289-2014, 2014.

Wang, Y., Li, A., Xi, P.-H., Chen, H., Xu, J., Wu, F.-C., Liu, J.-G., and Liu, W.-Q.: Retrieving vertical profile of aerosol extinction by multi-axis differential optical absorption spectroscopy, Acta Physica Sinica, 62, 180705, doi:10.7498/aps.62.180705, 2013.

Wang, Y., Li, A., Xie, P. H., Wagner, T., Chen, H., Liu, W. Q., and Liu, J. G.: A rapid method to derive horizontal distributions of trace gases and aerosols near the surface using multi-axis differential optical absorption spectroscopy, Atmos. Meas. Tech., 7, 1663-1680, doi:10.5194/amt-7-1663-2014, 2014.

Wang, Y., Penning de Vries, M., Xie, P. H., Beirle, S., Dörner, S., Remmers, J., Li, A., and Wagner, T.: Cloud and aerosol classification for 2.5 years of MAX-DOAS observations in Wuxi (China) and comparison to independent data sets, Atmos. Meas. Tech., 8, 5133-5156, doi:10.5194/amt-8-5133-2015, 2015.

Zieger, P., Weingartner, E., Henzing, J., Moerman, M., de Leeuw, G., Mikkilä, J., Ehn, M., Petäjä, T., Clémer, K., van Roozendael, M., Yilmaz, S., Frieß, U., Irie, H., Wagner, T., Shaiganfar, R., Beirle, S., Apituley, A., Wilson, K., and Baltensperger, U.: Comparison of ambient aerosol extinction coefficients obtained from in-situ, MAX-DOAS and LIDAR measurements at Cabauw, Atmos. Chem. Phys., 11, 2603-2624, doi:10.5194/acp11-2603-2011, 2011.

Zieger, P., Fierz-Schmidhauser, R., Weingartner, E., and Baltensperger, U.: Effects of relative humidity on aerosol light scattering: results from different European sites, Atmos. Chem. Phys., 13, 10609-10631, doi:10.5194/acp-13-10609-2013, 2013. 